\title{
National guidelines for dental diagnostic imaging in the developmental age
}

\author{
Maria Cristina Firetto ${ }^{1}$ - . Antonella Abbinante ${ }^{2}$. Ersilia Barbato ${ }^{3} \cdot$ Massimo Bellomi $^{4} \cdot$ Pietro Biondetti $^{1}$. \\ Andrea Borghesi $\mathrm{i}^{5} \cdot$ Maurizio Bossu' $^{\prime 3}$ - Piero Cascone ${ }^{3} \cdot$ Daniela Corbella $^{6} \cdot$ Vincenzo Di Candido $^{7} \cdot$ Paolo Diotallevi $^{8}$. \\ Giampiero Farronato $^{9} \cdot$ Antonio Federici $^{10} \cdot$ Massimo Gagliani $^{9} \cdot$ Claudio Granata $^{11} \cdot$ Mario Guerra $^{12}$. \\ Antonio MAGI ${ }^{13}$. Maria Cristina Maggio ${ }^{14}$. Stefano Mirenghi ${ }^{15} \cdot$ Michele Nardone $^{10} \cdot$ Daniela Origgi ${ }^{4}$. \\ Luigi Paglia $^{16}$. Lorenzo Preda ${ }^{4}$ Osvaldo Rampado ${ }^{17}$. Luigi Rubino ${ }^{18} \cdot$ Sergio Salerno $^{14} \cdot$ Angelo Sodano $^{19}$. \\ Alberto Torresin ${ }^{9} \cdot$ Laura Strohmenger $^{20}$
}

Received: 22 January 2019 / Accepted: 11 April 2019 / Published online: 4 May 2019

(C) Italian Society of Medical Radiology 2019

\section{Work Group}

On the recommendation of the "Technical Dentistry Group - GTO*" operating at the General Secretariat, the following professionals took part in drawing these guidelines:

Maria Cristina FIRETTO (Foundation IRCCS "Cà Granda"- Ospedale Maggiore Policlinico, Milan)

Antonella ABBINANTE (Italian Dental Hygienists Association - AIDI)

Ersilia BARBATO (University of Rome "Sapienza")

Massimo BELLOMI (European Institute of Oncology, Milan)

Pietro BIONDETTI (Foundation IRCCS Ca' Granda Ospedale Maggiore Policlinico, Milan)

Andrea BORGHESI (University of Brescia)

Maria Cristina Firetto

firettosirm@gmail.com

1 Foundation IRCCS “Cà Granda”- Ospedale Maggiore

Policlinico, Milan, Italy

2 Italian Dental Hygienists Association - AIDI, Rome, Italy

3 University of Rome "Sapienza", Rome, Italy

4 European Institute of Oncology, Milan, Italy

5 University of Brescia, Brescia, Italy

6 Local Health Unit Milano 2, Melegnano, Italy

7 Italian Society of Medical Radiology, Naples, Italy

8 Association for Research and Social Activities in Stomatology -ARASS, Rome, Italy

9 University of Milan, Milan, Italy

10 Ministry of Health, Rome, Italy

Maurizio BOSSU' (University of Rome "Sapienza") Piero CASCONE (University of Rome "Sapienza") Daniela CORBELLA (Local Health Unit Milano 2, Melegnano)

Vincenzo Di CANDIDO (Italian Society of Medical Radiology)

Paolo DIOTALLEVI (Association for Research and Social Activities in Stomatology -ARASS, Rome)

Giampiero FARRONATO (University of Milan)

Antonio FEDERICI (Ministry of Health)

Massimo GAGLIANI (University of Milan)

Claudio GRANATA (Institute "Giannina Gaslini", Genoa)

Mario GUERRA (Local Health Unit Umbria 1, Perugia) Antonio MAGI (Sindacato Unico Medicina Ambulatoriale Italiana e Professionalità dell'Area Sanitaria - SUMAI Trade Union Organisation)

11

12

13

Snico Medicina Ambulatoriale Italiana e Professionalità dell'Area Sanitaria - SUMAI Trade Union Organisation, Rome, Italy

14 University of Palermo, Palermo, Italy

15 National Association of Italian Dentists - ANDI, Rome, Italy

16 Italian Child Dentistry Society - SIOI, Rome, Italy

17 AOU "Health and Science City" of Turin, Turin, Italy

18 University of Genoa, Genoa, Italy

19 Italian Association of Dentists - AIO, Turin, Italy

20 W.H.O. Collaboration Centre for Epidemiology and Community Dentistry, Milan, Italy 
Maria Cristina MAGGIO (University of Palermo)

Stefano MIRENGHI (National Association of Italian

Dentists - ANDI)

Michele NARDONE (Ministry of Health)

Daniela ORIGGI (European Institute of Oncology, Milan)

Luigi PAGLIA (Italian Child Dentistry Society - SIOI)

Lorenzo PREDA (European Institute of Oncology, Milan)

Osvaldo RAMPADO (AOU "Health and Science City"

of Turin)

Luigi RUBINO (University of Genoa)

Sergio SALERNO (University of Palermo)

Angelo SODANO (Italian Association of Dentists - AIO)

Alberto TORRESIN (University of Milan)

Laura STROHMENGER (W.H.O. Collaboration Centre for Epidemiology and Community Dentistry, Milan) coordinator -

*Technical Dentistry Group: G. Nicoletti, C. Arcuri, P. Attanasi, G. Carnevale, B. Condorelli, P. De Logu, R. Gatto,
Diagnostic imaging in dental anomalies

Diagnostic imaging in dental traumatology

Table of Recommendations

Glossary

\section{Introduction}

Technological improvement in diagnostic imaging techniques and equipment has recently led to a great qualitative and quantitative improvement.

Dental imaging has dramatically changed over the last fifteen years, in particular in the field of oral surgery and paediatric dentistry. In both these specialties, scientific evidence has increased, highlighting the need for guidelines concerning radiation dose justification and optimisation in dental imaging.

As a matter of fact, several scientific articles and communications on dose issues in dental imaging increased, with particular focus on applied physics in medicine. In

E. Gherlone, G. Marzo, A. Federici, M. Nardone, G. Prada,

G. Renzo, L. Strohmenger.

\section{Ministry of Health}

$\underline{\text { Secretariat General }}$

Office 2

\section{National Guidelines for Dental Diagnostic Imaging in the Developmental Age}

November 2017

Introduction

Work Group

Bibliographical Research

Current regulations

Considerations on radiological risks and containment

strategies in $\mathrm{x}$-ray examinations

Diagnostic imaging for caries and periodontal disease

Diagnostic imaging in orthodontics and gnathology

Diagnostic imaging in cranio-maxillofacial malformations this sense, interest also arose in the international scientific community, leading to publication of guidelines by several institutions and societies $(1,2,3,4,5,6)$.

Among the campaigns for oral health promotion, in 2016 the National Department of Health decided to prepare guidelines on dental diagnostic imaging procedures in children and adolescents.

Therefore, a dedicated workgroup was created under the coordination of Prof. Laura Strohmenger, member of the W.H.O. Collaborating Centre for Epidemiology and Community Dentistry. 
This document aims to support the dental professional in choosing the adequate diagnostic technique, minimising the radiation dose in observance of the As Low As Reasonably Achievable (ALARA) principle (7). This principle states that the biological cost can only be justified when the benefit, that is, the diagnosis, outweighs the risk related to radiation exposure.

In this guideline paper, we report recommendations for radiologists, medical physicists, paediatrician, dentists and maxillofacial surgeons, with reference to the specific fields.

The diagnostic techniques considered in this paper are intraoral X-ray, orthopantomography (OPT), cephalometric (Ceph) x-ray and cone beam computed tomography (CBCT).

This work considers the Methodological Manual for National Guidelines System (2011), titled "How to produce, spread, and update Public Health Guidelines".

\section{Bibliographical research}

A systematic analysis of existing literature was carried out using PubMed, Embase and The Cochrane Library databases, with the following restrictions:

Publication date: From 2006/2004 to 2016/2004;

Species: Humans;

Age: Child: birth-18 years;

Language: English;

Article type: Guideline, Systematic Review.

When research did not produce exhaustive results, analysis was extended to non-systematic reviews and to randomised clinical trials.

Research was carried out by identifying specific Medical Subject Headings (MeSH) terms, checked on the NLM (National Library of Medicine) thesaurus and used for research, both individually and in mutual association, depending on their specificity with regard to the argument of the MeSH employed (Table 1a).

Terms were associated through Boolean operators (AND and OR)

Table 1a. Medical Subject Headings used for bibliographical research
From the identified publications, 185 articles and 7 web pages were selected, whose references are reported in this document.

For evaluation of the gathered documents, we used PRISMA (Preferred Reporting Items for Systematic Reviews and Meta-Analyses), one of the tools suggested by the Methodological Manual of the 2011 National Guidelines System "How to produce, disseminate and update public health guidelines".

\section{Bibliography}

- Guidelines for the safe use of dental and maxillofacial CBCT: a review with recommendations for South Africa. SADJ July 2011, vol. 66, No 6, page 262-266.

- SADMFR Guidelines for the use of Cone-Beam Computed Tomography/Digital volume tomography. Swiss Dental Journal SSO vol. 125 (9), 2015.

- Jerrold L. Seeding before doing. Am J Orthod Dentofacial Orthop 2014; 146:530-3.

- Dental radiographic examinations: recommendations for patient selection and limiting radiation exposure. America Dental Association, revision 2012.

- British orthodontic society revises guidelines for clinical radiography. D.L. Turpin. Am J Orthod Dentofacial Orthop 2008; 134:597-8.

- Orthodontic radiographs-guidelines for the use of radiographs in clinical orthodontics. K.G. Isaacson, A.R. Thom, K. Horner, E. Whaites, 3rd ed. London: British Orthodontic Society; 2008.

- ICRP, 1977. Recommendations of the International Commission on Radiological Protection. ICRP Publication 26.

\section{Recommendations}

These guidelines are based on the available scientific data, analysed based on the purpose of this document and on the participants' skills.

\begin{tabular}{|c|c|c|c|c|c|c|}
\hline Radiological field & & Patient field & & $\begin{array}{l}\text { Radiation protection } \\
\text { field }\end{array}$ & & Diagnostics field \\
\hline Dental radiology & & Child* & & Dose* & & Periodontal disease \\
\hline Dental radiography & & Adolescent & & Optimisation & & Dental decay \\
\hline Dental Cone Beam & & Paediatric & & Optimised & & Dental trauma \\
\hline Dental CBCT & AND & Age & AND & Radiation protection & AND & Orthodontic conditions \\
\hline Intraoral & & & & & & Jaw fracture \\
\hline Panoramic & & & & & & Dental anomalies \\
\hline Cephalometer* & & & & & & \\
\hline
\end{tabular}


Strong recommendations are based on the available highquality data from Guidelines and Systematic Reviews by meta-analysis.

Weak recommendations come from expert opinions and scientific data from lower evidence hierarchy.

Clinical options represent situations for which finding elements in favor or against was impossible.

Hierarchy of evidence and strength of recommendations were classified according to the instructions of the National Guidelines Plan:

Hierarchy of evidence
I $\quad \begin{aligned} & \text { Evidence from several controlled randomised clinical } \\ & \text { studies and/or from the systematic review of ran- } \\ & \text { domised studies, or from International Guidelines }\end{aligned}$
II $\quad \begin{aligned} & \text { Evidence from one single randomised study of suitable } \\ & \text { design }\end{aligned}$
III $\quad \begin{aligned} & \text { Evidence from non-randomised cohort studies with com- } \\ & \text { petitor or historical control, or their metanalysis }\end{aligned}$
IV $\quad \begin{aligned} & \text { Evidence from retrospective studies such as case-control } \\ & \text { or their metanalysis }\end{aligned}$
Evidence from series of case studies, without control
group
VI $\quad \begin{aligned} & \text { Evidence based on the opinion of authoritative experts } \\ & \text { or of expert committees, as indicated in the guidelines, } \\ & \text { or consensus conferences, or based on the opinions of } \\ & \text { members of this workgroup in charge of drawing the } \\ & \text { present guidelines }\end{aligned}$

Strength of recommendations

Execution of that particular procedure is strongly recommended. It indicates a recommendation backed up by good-quality scientific evidence, even if not necessarily of type I or II

B It is questionable whether that particular procedure or operation should always be recommended, but it should be carefully considered

C There is substantial uncertainty in favour of or against the recommendation to carry out the procedure or operation

D Execution of the procedure is not recommended

E It is strongly advised not to perform the procedure

\section{Current regulations}

Safeguarding the health of patients and other members of the population from medical ionising radiation bound risks is currently governed in Italy by Legislative Decree 187/00 and subsequent additions and modifications.

In this decree, the fundamental principles of radiation protection for justification and optimisation take the form of a regulatory constraint, with penalties for non-compliance.
In particular, Art. 3, sub-paragraph 2 states that: “a) all new types of practices involving medical exposure must be preliminarily justified before being generally adopted; b) existing types of practices involving medical exposure may be reviewed every time new and relevant evidence concerning their efficacy is acquired".

It is therefore clear that justification is an ever evolving conceptual and regulatory process, especially considering the spreading of new technologies, such as cone beam computed tomography (CBCT), which leads to an evolution in diagnostic information access. For these appliances, the Italian Ministry of Health drew the "Recommendations for the correct use of CBCT equipment" (Official Bulletin No 124 of 29/05/2010 http://www.gazzettaufficiale.it/eli/ $\mathrm{id} / 2010 / 05 / 29 / 10 \mathrm{~A} 06042 / \mathrm{sg}$ ).

Art. 4 "Principle of optimisation" introduces the diagnostic reference levels (DRL) with the aim of providing a working tool to guarantee an optimisation process standardisation for the most common radiological practices. These are easily measureable dose-level thresholds that should never be exceeded in normal examination of average build patient groups, and for well-defined appliances and techniques. In the field of dental radiological imaging, there are currently no defined DRLs in Italy, whereas some DRL values defined in other countries will be illustrated in a dedicated section of this document.

Specific aspects regarding apparatuses are featured in Art. 8, including the obligation to define quality assurance programmes, to make acceptance and performance tests, and for the head of radiological equipment to state their clinical adequacy. All these aspects are particularly significant in the context of "special practices" defined by Art. 9, meaning medical exposures concerning children, screening programmes and techniques involving high doses for the patient, such as interventional radiology and computed tomography. So, within the context of these guidelines purpose, it is highlighted that all dental radiological practices involving exposure of paediatric patients must be considered as special practices, in accordance with the above-mentioned Art. 9. All provisions of the latter article must therefore be adhered to, including periodic dosimetric assessments by a medical physics expert, based on which the head of radiological equipment shall judge the technical service quality and the diagnostic procedure.

Generally, in the current regulatory framework and in particular with regard to the implementation modes, the European Guidelines on radiation protection must be taken into consideration. Among these, we point out:

- "European guidelines on radiation protection in dental radiology—No 136" [1] 
- "Criteria for acceptability of medical radiological equipment used in diagnostic radiology, nuclear medicine and radiotherapy-No 162" [2]

- "Cone beam CT for dental and maxillofacial radiologyNo 172" [3]

Moreover, the reference technical regulations defined by the Italian Electrotechnical Committee are of fundamental importance in verifying the equipment technical features. In the field of dental radiology, the following may be considered:

- IEC EN 60601-2-63 "Medical electrical equipment Part 2: Particular requirements for the basic safety and essential performance of dental extra-oral X-ray equipment" [4]

- IEC EN 60601-2-65 "IEC Classification: 62-235 Medical electrical equipment Part 2: Particular requirements for the basic safety and essential performance of intraoral dental X-ray equipment" [5]

\section{Updating}

These guidelines will be updated also following transposition of Directive 2013/59/Euratom and every 4 years, unless the basis of the evidence should change earlier, thus making these recommendations obsolete or in need of upgrading.

\section{Monitoring}

Efficacy of these guidelines will be assessed over time, by measuring the variations in certain clinical indicators, as described by the World Health Organisation.

\section{Considerations on radiological risks and containment strategies in X-ray examinations}

\section{What are the risks associated with diagnostic radiological dental examinations during development?}

Radiological diagnosis in dentistry is based mainly on intraoral radiography, orthopantomography, computed tomography (CT) and, more recently, cone beam CT. All these methods use $\mathrm{X}$-rays and thus ionising radiation that may interact at a cellular level.

When ionising radiation passes through a cell, there may be ionisations of atoms in the molecules that constitute the cell itself. These ionisation phenomena may lead to molecular damage of varying degree depending on the type and quantity of radiation, and the characteristics of the cell itself. The cellular structure most sensitive to ionising radiation is the DNA, which may be damaged following exposure to ionising radiation. Damage to the DNA may be entirely repaired by means of complex mechanisms; it may be irreparable, with consequent cellular death; or it may be partially repairable with the consequent appearance of a genetic mutation. This mutation could be the primum movens of a complex series of events potentially resulting in carcinogenesis or, in the case of the involvement of germ cells, causing hereditary diseases in the radiated persons' progeny.

The biological effects of ionising radiation may be grouped in deterministic effects and stochastic effects.

Deterministic effects are caused by exposure to ionising radiation doses that are far higher than those used in radiological diagnostics, occurring only if specific threshold values are exceeded and with a gravity that increases with an increase in the absorbed dose. They are caused by cellular death and may manifest themselves in pancytopenia, alopecia, sterility, burns, pneumonia and serious gastrointestinal disturbances, with possible death of the radiated person.

Stochastic effects are caused by radiation doses lower than those required for the manifestation of deterministic effects and are due to non-lethal and unrepaired cells damage that may become manifest with a variable latency, even of several years.

For the purposes of radiation protection, the accepted assumption is that there is a linear relationship between risk and radiation dose, and that there is no threshold value below which risk is zero. On the basis of this assumption, the risk associated with the execution of specific radiological examinations may be estimated. At present, however, the form of relationship between low doses of ionising radiation — such as those used in radiological imaging — and the manifestation of stochastic effects is not clear. It may indeed be the case that the risk is lower than that estimated using the above-mentioned linear no-threshold model. In the absence of certainty in this regard, a prudential approach is preferred to ensure that the dose of radiation employed for radiological diagnostics is the minimum indispensable for producing an image of adequate diagnostic quality.

The absorbed dose for ionising radiation may be defined as the quantity of energy deposited in the exposed tissues or organs. It is measured in gray (Gy), where $1 \mathrm{~Gy}$ is equal to one joule of energy absorbed by a one $\mathrm{kg}$ mass of tissue. The Gray is a very large unit of measurement in diagnostic imaging so it is therefore more practical to use the milliGray as unit of measurement, corresponding to one thousandth of a Gray. 
The risks due to exposure to different types of ionising radiation may be compared in terms of equivalent dose. The equivalent dose for a given type of radiation is defined by using (i.e. multiplying the absorbed dose by) a weighting factor specific to that type of radiation, which in the case of $\mathrm{X}$ - and gamma-rays is equal to 1 , and can be higher for other types of ionising radiation.

The effective dose is the weighted sum of the equivalent dose in a series of tissues or organs, using weighting factors specific to each of the tissues on the basis of their susceptibility to the onset of radio-induced cancers. The concept of effective dose is a tool for both occupational and general population radiation protection. It may be used for the comparison of doses originating from different diagnostic examinations and interventional procedures. Moreover, the effective dose allows comparison of doses resulting from different techniques employed for the same medical examination and/or comparison of doses resulting from similar procedures carried out in several institutions. The effective dose is not, however, conceived to give an accurate estimate of the risk associated with a given radiation exposure for a single individual The organs dose-both in terms of absorbed dose and of equivalent dose-appears to be more appropriate for the assessment of individual risk.

The risk of developing a malignant neoplasm during one's lifetime is around $42 \%$ (i.e. in the course of their lifetime almost one out of every two people will suffer a malign neoplasm). This is the so-called lifetime baseline risk (LBR). The additional risk of developing a malignant tumour following exposure to ionising radiation is known as "lifetime attributable risk" (LAR). The LAR is correlated with sex and age at time of exposure and is calculated on the basis of risk models drawn from epidemiological studies carried out with survivors of the bombing of Hiroshima and Nagasaki, supplemented with data on individuals exposed to ionising radiation for clinical or professional reasons.

On the basis of the risk assessment model proposed by the National Academy of Sciences in the report "Biological Effects of Ionizing Radiation VII" (BEIR VII), exposure to $1 \mathrm{mSv}$ (the average national per capita dose originating from execution of diagnostic procedures for adults) involves a LAR of developing a tumour equal to 5 cases per 100.000 adults. With risk depending on age, it diminishes to $1-2$ cases per 100.000 for people over 60 and increases to $10-15$ cases per 100.000 for children. It follows that the risk must always be kept in mind, especially in the case of using radiological procedures that expose patients to high doses of radiation, this being justifiable only when there is a clear benefit to the patient deriving from execution of the procedure itself.
Radiological diagnostic procedures typically involve an exposure of less than $1 \mathrm{mSv}$, though CT examinations may involve exposure to doses of several $\mathrm{mSv}$. For radiological procedures in the dental field, the scientific reference literature consistently reports the values of effective dose and equivalent dose to be at levels of microSieverts $(\mu \mathrm{Sv})$, where one $\mu \mathrm{Sv}$ is equal to one thousandth of an $\mathrm{mSv}$. In the context of CBCT procedures in dentistry during the developmental years, Ludlow's recent review [1] provides a metanalysis of assessments of effective doses with paediatric protocols and phantoms, derived from the use of 10 different apparatuses. The assessments are subdivided into those deriving involving the use of a medium or large field of view (height greater than $10 \mathrm{~cm}$ ) or small field of view (height less than $10 \mathrm{~cm}$ ) for maxillary bone and for mandible. Table 1 shows the median values and the minimum-maximum ranges of the main dosimetric quantities. Figures 1 and 2 illustrate the box-and-whisker plots of the distributions of values, also with indication of the interquartile range. Ludlow underscores that the effective dose assessed using paediatric simulation phantoms with CBCT apparatuses is around $36 \%$ greater than that found with adult phantoms, an increase to be correlated mainly with the greater proximity of the thyroid to the inferior margin of the jaw in children, with the consequence of a greater irradiation, both direct and as scatter from the maxillary structures. The consideration on greater closeness to the irradiation zone is also valid for the nerve structures.

The magnitude and the wide range of variabilities of the values shown underline the importance of an attentive assessment of clinical justification prior to exposing paediatric patients to a CBCT examination, and of the optimisation criteria that allow positioning in the low part of the distributions shown, aspects which will be widely recalled in the various recommendations in these guidelines.

Table 1. Median values of effective dose, thyroid and salivary glands doses for a range of CBCT equipments and protocols employed on paediatric simulation phantoms [1]

\begin{tabular}{llll}
\hline FOV & Effective dose & Dose to thyroid & $\begin{array}{l}\text { Dose to salivary } \\
\text { glands }\end{array}$ \\
\hline $\begin{array}{l}\text { Small maxillary } \\
\text { bone }\end{array}$ & 44 & 227 & 1930 \\
Small jaw & 80 & $(53-575)$ & $(438-4974)$ \\
& $(24-331)$ & $(327-3382)$ & 1654 \\
Medium or & 127 & 1003 & 2045 \\
large & $(39-430)$ & $(384-4265)$ & $(531-6622)$ \\
\hline
\end{tabular}

The values in brackets are the minimum-maximum range. 


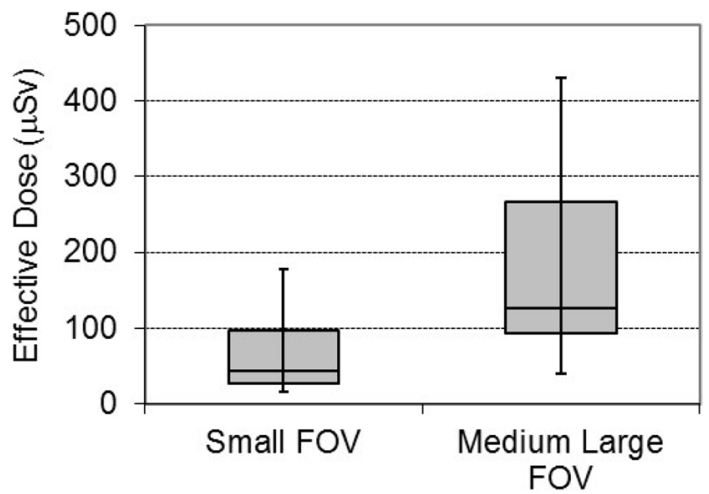

Fig. 1: Effective dose distributions for the range of equipment used for CBCT examinations of paediatric patients in [1].

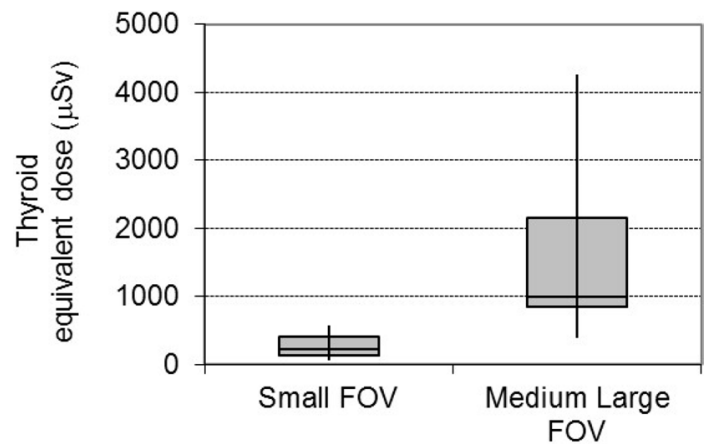

Fig. 2: Distributions of equivalent dose to thyroid and salivary for the range of equipments used for CBCT examinations of paediatric patients in [1].

\section{What is(are) the meaning(s) of the dosimetric quantities and of the patient dose indicators?}

With a view to supplying operators with an operational indication of the ionising radiation exposure for every examination carried out, dose indicators for the patient have been defined, specific to the different radiological methodologies. Unlike the dose absorbed by the organs or the effective dose, which require a complex assessment procedure, these can be easily measured with an instrument integrated into the radiological apparatus or calculated from the exposure parameters (e.g. voltage, anodic current, acquisition time, X-ray beam dimension) so their value may be visualised immediately at the end of the examination. If the assessment is carried out by calculation, the value is available at the same time as the choice of protocol, even before acquisition. These indicators are defined by scientific bodies in the radiology and medical physics sector, and their adoption is rendered operational through the reference technical regulations. The availability of such dosimetric indicators makes it feasible to carry out multicentric data gathering that, with appropriate statistical analyses, can be used to define diagnostic reference levels.

The obligation to have this dose indication available is prescribed by the Italian regulations $187 / 00$ in article 8 , subparagraph 8: "In the case of utilisation of a newly installed radiodiagnostic equipment, this must be equipped, if feasible, with a device that informs the specialist about the quantity of ionised radiation produced by the device during the radiological procedure". The latest European directive on the subject of protection from ionising radiation (2013/59/ Euratom), currently being integrated into the national regulations, confirms this obligation and, moreover, prescribes the recording of the pertinent parameters for assessment of the dose to the patient for each examination. The new directive further prescribes that the information regarding the patient's exposure should be part of the medical-radiological procedure report.

The table below shows the dose indicators used in the dental radiology field:

Table 2. Indicators of doses used in the various apparatuses for dental radiology

\begin{tabular}{llll}
\hline Magnitude & $\begin{array}{l}\text { Unit of measurement } \\
\text { normally used }\end{array}$ & Apparatus on which used & Definition \\
\hline $\begin{array}{l}\text { Air kerma }\left(\mathrm{K}_{\text {air }}\right) \\
\text { or }\end{array}$ & $\mathrm{mGy}$ & Intraoral & $\begin{array}{c}\text { Air kerma value measured in correspondence to the } \\
\text { entrance of the beam into patient }\end{array}$ \\
$\begin{array}{l}\text { Entrance skin air kerma (ESAK) } \\
\text { Entrance skin dose (ESD) }\end{array}$ & $\mathrm{mGy}$ & $\begin{array}{l}\text { Cephalometry unit } \\
\text { Dose area product (DAP) }\end{array}$ & $\begin{array}{l}\text { Dose value resulting from product of air kerma and } \\
\text { backscatter factor measured in correspondence to } \\
\text { entrance of beam into patient }\end{array}$ \\
$\begin{array}{l}\text { Kerma area product (KAP) } \\
\text { Computed tomography dose index } \\
(\mathrm{CTDI})\end{array}$ & $\mathrm{mGy}$ & $\begin{array}{l}\text { Intraoral, } \\
\text { orthopantomograph, ceph- } \\
\text { alometry unit, CBCT } \\
\text { Multislice CT }\end{array}$ & $\begin{array}{c}\text { Product of the area of a radiological beam section } \\
\text { and the average air kerma on that section }\end{array}$ \\
\hline
\end{tabular}


Kerma (Kinetic Energy Released per unit Mass) means the kinetic energy transferred by the $\mathrm{X}$ photons to the charged particles of the irradiated material: for the $\mathrm{x}$-ray energies used in radiodiagnostics, its air value coincides with the value of the dose, and therefore, the two terms may be used in an equivalent manner. The ESAK (Entrance Skin Air Kerma) for an intraoral apparatus therefore corresponds to the air dose assessed on the axis of the beam at the exit of the cylinder and is a quantity directly proportional to the duration of exposure and to the intensity of the anodic current. The ESD (Entrance Skin Dose) is used for the diagnostic reference levels of the most common projections of radiodiagnostics (Enclosure II Italian Legislative Decree 187/00), and its value corresponds to that of the air kerma multiplied by a "backscatter factor" which takes backscattered radiation into consideration and which typically assumes values between 1.3 and 1.4. The DAP (Dose Area Product) takes into account of both the intensity of the beam and its dimensions, and its assessment does not depend on the distance from the source for which it is evaluated. The quantity CTDI (Computed Tomography Dose Index) is used for CT equipment, and until a few years, ago was also used for CBCT, but for the latter it has now been replaced by DAP.

In the field of intraoral equipment, the standard IEC EN 60601-2-65 [3] prescribes that newly installed devices should supply the air kerma value at a pre-established distance. It is, moreover, required that the apparatus documentation should include a method for calculating DAP on the basis of the air kerma and of the size of the radiation beam.

Standard IEC EN 60601-2-63 [4] concerning the essential capacities of extraoral X-ray dental equipment (therefore orthopantomographs and CBCT) prescribes that these devices should indicate the DAP. In the European guidelines [5] as well, indication of the DAP is required for all protocols and the variations in selectable parameters on each CBCT equipment. Where these data are not available on already installed devices, the medical physics expert in charge of dosimetry must measure and tabulate them in such a way that the clinician can take account of these indicators in the choice of the protocols to use. In the case of availability of these data, the medical physics expert must check their accuracy, with a maximum acceptable tolerance of $50 \%$.

\section{What are the typical dose indicator values given in the literature for the various examinations?}

In the absence of diagnostic reference levels defined at European or national level, the dosimetric indicators presented in the previous paragraph and available with newly installed radiological equipment may be compared with the values published in the literature. The values given in the following tables refer to a bibliographical research carried out on studies published from the year 2000 onwards.

As for intraoral apparatuses, three multicentric data collections have been identified that focus on statistical analysis of dosimetric indicators in the utilisation of parameters for paediatric patients.

Table 3. Values of dose indicators in the literature for intraoral apparatuses used with paediatric patients

\begin{tabular}{|c|c|c|c|}
\hline Reference & $\begin{array}{l}\text { Mag- } \\
\text { nitude } \\
\text { utilised }\end{array}$ & Data & Typology of datum \\
\hline Hart 2009 [6] & ESAK & $1.5 \mathrm{mGy}$ & $\begin{array}{l}\text { Paediatric diagnos- } \\
\text { tic reference level } \\
\text { resulting from data } \\
\text { analysis of } 3000 \\
\text { centres in Great } \\
\text { Britain }\end{array}$ \\
\hline Looe 2006 [7] & DAP & $\begin{array}{l}\text { Differentiated } \\
\text { for the various } \\
\text { projections from } \\
14.4 \mathrm{mGy} \mathrm{cm}{ }^{2} \\
\text { for incisors to } \\
40.9 \text { mGy cm } \\
\text { for molars }\end{array}$ & $\begin{array}{l}\text { Average values } \\
\text { resulting from } \\
\text { analysis of } 52 \text { cen- } \\
\text { tres in Germany, } \\
\text { considering only } \\
\text { equipment with } \\
\text { dedicated paediat- } \\
\text { ric protocols }\end{array}$ \\
\hline Bekas 2013 [8] & ESD & $\begin{array}{l}\text { From } 0.69 \text { to } \\
0.84 \mathrm{mGy} \\
\text { depending on } \\
\text { projection con- } \\
\text { sidered }\end{array}$ & $\begin{array}{l}\text { Average values from } \\
\text { analysis of } 72 \\
\text { centres in Poland, } \\
\text { considering paedi- } \\
\text { atric protocols }\end{array}$ \\
\hline
\end{tabular}

With regard to orthopantomographs, the data deriving from studies published between 2004 and 2014 show DAP values from 77 to $96 \mathrm{mGy} \mathrm{cm}^{2}$. Guidelines RP162 [9], with reference to minimum criteria of acceptability for radiological apparatuses, consider unacceptable in any case a DAP for a panoramic radiography greater than $100 \mathrm{mGy} \mathrm{cm}^{2}$, even for adult patients.

Table 4. Values of dose indicators in the literature for orthopantomographs used with paediatric patients

\begin{tabular}{llll}
\hline Reference & $\begin{array}{l}\text { Mag- } \\
\text { nitude } \\
\text { utilised }\end{array}$ & Data & Typology of datum \\
\hline Kim 2014 [10] & DAP & $95.9 \mathrm{mGy} \mathrm{cm}^{2}$ & $\begin{array}{l}\text { Value identified as } \\
\text { third quartile of } \\
\text { distribution data } \\
\text { of 28 Korean } \\
\text { centres }\end{array}$ \\
Hart 2009 [6] & DAP & $82 \mathrm{mGy} \mathrm{cm}^{2}$ & $\begin{array}{l}\text { Diagnostic refer- } \\
\text { ence level result- } \\
\text { ing from data } \\
\text { analysis of 3000 } \\
\text { centres in Great } \\
\text { Britain }\end{array}$ \\
\hline & & & \\
& & &
\end{tabular}




\begin{tabular}{llll}
\hline Reference & $\begin{array}{l}\text { Mag- } \\
\text { nitude } \\
\text { utilised }\end{array}$ & Data & Typology of datum \\
\hline Poppe 2007 [11] & DAP & $75.4 \mathrm{mGy} \mathrm{cm}^{2}$ & $\begin{array}{l}\text { Diagnostic } \\
\text { reference level } \\
\text { resulting from } \\
\text { data analysis } \\
\text { of } 50 \text { centres in } \\
\text { Germany }\end{array}$ \\
Tierris 2004 [12] & DAP & $77 \mathrm{mGy} \mathrm{cm}^{2}$ per & $\begin{array}{l}\text { Diagnostic refer- } \\
\text { ence level result- } \\
\text { ing from data } \\
\text { analysis of } 62 \\
\text { centres in Greece }\end{array}$ \\
& & DAP & \\
& &
\end{tabular}

For cephalometry units, only two studies were identified, with very different DAP values.

Table 4. Values of dose indicators in the literature for cephalometry units used with paediatric patients

\begin{tabular}{llll}
\hline Reference & $\begin{array}{l}\text { Mag- } \\
\text { nitude } \\
\text { utilised }\end{array}$ & Data & Typology of datum \\
\hline Kim 2014 [10] & DAP & $121.3 \mathrm{mGy} \mathrm{cm}^{2}$ & $\begin{array}{l}\text { Diagnostic reference } \\
\text { level resulting } \\
\text { from data analysis } \\
\text { of 20 centres in } \\
\text { Korea }\end{array}$ \\
Holroyd 2011 [13] DAP & $25 \mathrm{mGy} \mathrm{cm}^{2}$ & $\begin{array}{l}\text { Diagnostic reference } \\
\text { level resulting } \\
\text { from data analysis } \\
\text { of 27 centres in } \\
\text { Great Britain }\end{array}$ \\
& & & \\
& &
\end{tabular}

For CBCT equipment, to date there are no published studies with multicentric data collection of dosimetric indicators. The table below shows the average DAP values for paediatric protocols used on 10 different CBCT equipments.

Table 5. Values of dose indicators in the literature for CBCT with protocols for paediatric patients

\begin{tabular}{|c|c|c|c|}
\hline Reference & $\begin{array}{l}\text { Magnitude } \\
\text { utilised }\end{array}$ & Data & $\begin{array}{l}\text { Typology of } \\
\text { datum }\end{array}$ \\
\hline $\begin{array}{l}\text { Ludlow } 2015 \\
\text { [1] }\end{array}$ & DAP & $\begin{array}{l}\text { FOV large } \\
\text { and medium } \\
529 \mathrm{mGy} \mathrm{cm}^{2} \\
\text { FOV small } \\
\text { maxillary } \\
121 \mathrm{mGy} \mathrm{cm}{ }^{2} \\
\text { FOV small jaw } \\
153 \mathrm{mGy} \mathrm{cm}^{2}\end{array}$ & $\begin{array}{l}\text { Average values } \\
\text { deriving from } \\
\text { the setting } \\
\text { of paediatric } \\
\text { protocols on } \\
10 \text { different } \\
\text { apparatuses }\end{array}$ \\
\hline
\end{tabular}

\section{What characteristics must the acquisition protocols and parameters have for radiodiagnostic dental examinations in the developmental years?}

In general, studies published in recent years underline the need to define acquisition protocols with parameters adapted to the reduced dimensions and the diagnostic requirements specific for the paediatric patient, with the published multicentric assessments often highlighting the use of inadequate parameters.

An Anglo-Saxon study of 2013 [15] of intraoral examinations showed the national diagnostic reference level to be exceeded in $35 \%$ of the operational modes used for adult patients and in no less than $61 \%$ of those used for paediatric patients. The same study highlights how, notwithstanding the fact that the technological evolution of digital detectors and collimation systems offers the possibility of significant dose reductions, in many cases the technical parameters used lead to patient exposures greater than those required to obtain the correct diagnostic information.

A Finnish work of 2015 [16] presents an investigation carried out on 241 orthopantomographs and 118 cephalometric units used on paediatric patients: the panoramic images turned out to be wider than necessary in $70 \%$ of the cases and of greater length in $96 \%$. Cephalometric radiographs also turned out to be larger than necessary in more than $50 \%$ of cases. Thyroid protection was used in roughly $71 \%$ of cases.

"Image Gently" is an awareness-raising and educational campaign concerning proper radiological risk management for paediatric patients, promoted by American scientific associations in the paediatric and radiology field. They have summarised in the following six steps the key points for minimising dose in dental radiology practices in the developmental years [17]:

- selection of radiological images in conformity with the patient's specific needs;

- the use of detectors with maximum sensitivity (high speed in the case of film or equivalent digital systems);

- collimation of the beam on the area of interest;

- use of thyroid collar for all intraoral examinations, and for extraoral examinations when it does not interfere with the area under examination;

- suitable reduction in exposure parameters (time, intensity of anodic currents, etc.) in comparison with parameters employed for adult patients;

- use of CBCT only when necessary. 
Among the most common technical errors that might cause artifacts in the images, one must consider:

- carrying out examinations in the presence of hairclips, metal jewellery, food in the mouth (sweets, chewing gum), removable dental prostheses;

- incorrect positioning of the patient;

- incorrect positioning of the tongue;

- errors in limiting patient movement during image acquisition.

The main actions to be adopted in order to reduce the frequency of these errors are:

- programme suitable child-friendly time schedules for preparing and carrying out the examination, longer than those necessary for adults;

- train staff in suitable communications skills with kids and their families;

- calm the patient: in the case of excessive anxiety and restlessness, do not insist; if necessary, postpone the session;

- check also with the parents that jewellery, hairclips and dental prostheses have been removed, as well as sweets or gum from the child's mouth;

- pay great attention to correct positioning of the patient (neck, back, shoulders);

- without rush or fuss, show the patient the correct positioning of the tongue (in contact with the palate);

- for teleradiography of the cranium: in the case of roll, pitch or rotation, always consider carefully the real need to repeat the examination; most errors influence assessment of the main angles [18].

The 2012 document "Radiation Protection 162" [9] defines new acceptability criteria for technical and functional parameters of all radiological apparatuses, including those used in the dental sector. In particular, the following are considered unacceptable for intraoral apparatuses:

- the use of analogue film with class lower than E for which there is no specific justification;

- the use of a non-rectangular collimation for which there is no specific justification;

- a rectangular collimation in a field greater than $40 \times 50 \mathrm{~mm}$

In particular, the required use of rectangular collimation with a field less than $40 \times 50 \mathrm{~mm}$ may not be supported or in any case it is difficult to apply for portable intraoral apparatuses, as evidenced in the EADMER position paper [10]. In the same document, it is underlined that this kind of equipment generally works with lower voltage and $\mathrm{mA}$ at conventional intraoral examinations, involving the need to increase the exposure times which, coupled with the method of positioning the apparatus, augments the risk of movement artefacts. So special attention must be paid to justification of the use of these devices and, while awaiting further evidence from the literature, it is expected that their use will remain limited to very particular cases where it is not effectively possible to employ a fixed intraoral unit.

In drawing up these guidelines, comparative evaluation of the recent reference bibliography has allowed the formulation of the following recommendations.

\section{Recommendation 1}

Orthopantomography units frequently used on paediatric patients must provide protocols with reduced beam intensity and acquisition fields limited to the area of interest

Strength of recommendation: A Degree of Evidence: IV A reduction in effective dose of around 30\% and reductions in dose to the organs of more than $50 \%$ are seen in the study [19], thanks to the use of a radiation field height of $11 \mathrm{~cm}$ instead of the standard adult height of $14 \mathrm{~cm}$.

\section{Recommendation 2}

Cephalometric units frequently used on paediatric patients must have the possibility of collimating the beam to the area of interest

Strength of recommendation: A Degree of Evidence: IV Numerous studies report the possibility of reducing dose by more than $50 \%$ through the use of specially defined collimations for cephalometric examinations on paediatric patients $[20,21]$.

\section{Recommendation 3}

Cone beam CT units frequently used on paediatric patients must provide the possibility of using fields of view no larger than the area of diagnostic interest and to define reduced exposure parameters compared to the settings used for adult patients

Strength of recommendation: A Degree of Evidence: IV Recent dosimetric studies [22, 23] show that the use of an adult protocol on a paediatric patient may involve unjustified exposure doses. Limiting the FOV in line with the other parameters and compatibly with diagnostic requirements is in general a rule to follow in order to minimise the dose to the paediatric patient. There are, however, studies 
showing that with some equipment a reduction in FOV may be associated with an increase in other exposure parameters, as the beam intensity, such that the dose may even be greater [24]. It is, therefore, necessary to pay attention to all the parameters associated with the different equipment settings, and in order to compare them from a dose viewpoint, it is appropriate to refer to the DAP indication supplied.

A recent study by Pauwels [25] evaluated image quality indices on variation in the anatomical dimension concerned. The results show the possibility of reducing the dose in the paediatric field by maintaining the $\mathrm{kV}$ value relatively high $(90 \mathrm{kV}$ on the apparatus examined) and reducing the value of the $\mathrm{mAs}$ prescribed for an adult by $40 \%$ for paediatric patients of around 3 years old and by $20 \%$ for those around 10 years old.

\section{Recommendation 4}

The lead thyroid collar contributes significantly to reducing the dose to the thyroid for all radiodiagnostic dental examinations in the developmental years. In the context of $C B C T$, it is particularly recommended for extended fields, except in cases where, at the time of positioning the patient, the technician, the radiologist or the specialist ascertains there to be a risk of artifacts or possible superimpositions with regard to the anatomical structures of interest. As for cephalometry, the use is recommended where there is no need to visualise bony structures below the second cervical vertebra

Strength of recommendation: A Degree of Evidence: IV The assessments made by Hidalgo [26] on a CBCT apparatus with FOV diameter $17 \mathrm{~cm}$ and height $12 \mathrm{~cm}$, and with various types of thyroid collar, show dose reductions to the thyroid of between approximately 20 and $40 \%$.

Numerous recent studies [27, 28, 29] highlight the compatibility of thyroid protection in carrying out cephalometry on paediatric patients, which involves a significant reduction in the dose at the thyroid, with the limitation that the bone structures represented start from the second cervical vertebra.

\section{Bibliography}

- Ludlow JB, Timothy R, Walker C, Hunter R, Benavides E, Samuelson DB, Scheske MJ. Effective dose of dental CBCT-a metanalysis of published data and additional data for nine CBCT units. Dentomaxillofac Radiol. 2015;44(1):20140197.

- ICRU Report No. 87: Radiation dose and image-quality assessment in computed tomography. International Commission on Radiation Units and Measurements. J ICRU.
2012 Apr;12(1):1-149. https://doi.org/10.1093/jicru/ ndt007.

- IEC 62-235 IEC EN 60601-2-65:2013-11 (English) Apparecchiature elettromedicali-Parte 2: Prescrizioni particolari relative alla sicurezza fondamentale e alle prestazioni essenziali degli apparecchi dentali intraorali a raggi $X$.

- IEC 62-248 IEC EN 60601-2-63:2016-06 (English) Apparecchi elettromedicali-Parte 2: Prescrizioni particolari relative alla sicurezza fondamentale e alle prestazioni essenziali degli apparecchi dentali extraorali a raggi $X$.

- European Commission Radiation Protection No 172 «Cone Beam CT for dental and maxillofacial radiology-Evidence Based Guidelines» Directorate-General for Energy Directorate D-Nuclear Energy Unit D4Radiation Protection 2012.

- Hart D, Hillier MC, Wall BF. National reference doses for common radiographic, fluoroscopic and dental X-ray examinations in the UK. Br J Radiol. 2009 Jan;82(973):1-12.

- Looe HK, Pfaffenberger A, Chofor N, Eenboom F, Sering M, Ruhmann A, Poplawski A, Willborn K, Poppe B. Radiation exposure to children in intraoral dental radiology. Radiat Prot Dosimetry. 2006;121(4):461-5.

- Bekas M, Pachocki KA. The dose received by patients during dental X-ray examination and the technical condition of radiological equipment. Med Pr. 2013;64(6):755-9.

- European Commission Radiation Protection No 162 «Criteria for Acceptability of Medical Radiological Equipment used in Diagnostic Radiology, Nuclear Medicine and Radiotherapy» Directorate-General for Energy Directorate D-Nuclear Energy Unit D4Radiation Protection 2012.

- Berkhout WE, Suomalainen A, Brullmann D, Jacobs R, Horner K, Stamatakis HC Justification and good practice in using handheld portable dental X-ray equipment: a position paper prepared by the European Academy of DentoMaxilloFacial Radiology (EADMFR). Dentomaxillofac Radiol. 2015;44(6).

- Kim YH, Yang BE, Yoon SJ, Kang BC, Lee JS. Diagnostic reference levels for panoramic and lateral cephalometric radiography of Korean children. Health Phys. 2014 Aug;107(2):111-6.

- Poppe B, Looe HK, Pfaffenberger A, Chofor N, Eenboom F, Sering M, Ruhmann A, Poplawski A, Willborn K. Dose-area product measurements in panoramic dental radiology. Radiat Prot Dosimetry. 2007;123(1):1314.

- Tierris CE, Yakoumakis EN, Bramis GN, Georgiou E. Dose area product reference levels in dental panoramic radiology. Radiat Prot Dosimetry. 2004;111 (3):283-7. 
- Holroyd JR. National reference doses for dental cephalometric radiography. Br J Radiol. 2011 Dec;84(1008):1121-4.

- Hart G, Dugdale M. Radiation protection in dental X-ray surgeries-still rooms for improvement. Br Dent J. 2013 Mar;214(6).

- Pakbaznejad Esmaeili E, Ekholm M, Haukka J, Evalahti M, Waltimo-Sirén J. Are children's dental panoramic tomographs and lateral cephalometric radiographs sufficiently optimized? Eur J Orthod. 2015, Oct 19.

- Law CS, Douglass JM, Farman AG, White SC, Zeller GG, Lurie AG, Goske MJ. The image gently in dentistry campaign: partnering with parents to promote the responsible use of $\mathrm{x}$-rays in pediatric dentistry. Pediatr Dent. 2014 Nov-Dec;36(7):458-9.

- Blanc M, Garattini G, Moruzzi E. Lateral teleradiography of the cranium: the effect of head positioning in the interpretation of cephalometric tracings. An experimental study on a phantom. Radiol Med. 1997 0ct;94(4):302-7.

- Davis AT, Safi H, Maddison SM. The reduction of dose in paediatric panoramic radiography: the impact of collimator height and programme selection. Dentomaxillofac Radiol. 2015;44(2):20140223.

- Alcaraz M, Garcia-Vera MC, Bravo LA, Martmez-Beneyto Y, Armero D, Morant JJ, Canteras M. Collimator with filtration compensator: clinical adaptation to meet European Union recommendation 4F on radiological protection for dental radiography. Dentomaxillofac Radiol. 2009 Sep;38(6):413-20.

- Gijbels F, Sanderink G, Wyatt J, Van Dam J, Nowak B, Jacobs R. Radiation doses of collimated Vs non-collimated cephalometric exposures. Dentomaxillofac Radiol. 2003 Mar;32(2):128-33.

- Choi E, Ford NL. Measuring absorbed dose for i-CAT CBCT examinations in child, adolescent and adult phantoms. Dentomaxillofac Radiol. 2015;44(6):20150018.

- Al Najjar A, Colosi D, Dauer LT, Prins R, Patchell G, Branets I, Goren AD, Faber RD. Comparison of adult and child radiation equivalent doses from 2 dental cone-beam computed tomography units. Am J Orthod Dentofacial Orthop. 2013 Jun;143(6):784-92.

- Abouei E, Lee S, Ford NL. Quantitative performance characterization of image quality and radiation dose for a CS 9300 dental cone beam computed tomography machine. J Med Imaging (Bellingham). 2015 0ct;2(4):044002.

- Pauwels R, Jacobs R, Bogaerts R, Bosmans H, Panmekiate $\mathrm{S}$. Determination of size-specific exposure settings in dental cone-beam CT. Eur Radiol. 2016 Apr 23.

- Hidalgo A, Davies J, Horner K, Theodorakou C. Effectiveness of thyroid gland shielding in dental CBCT using a paediatric anthropomorphic phantom. Dentomaxillofac Radiol. 2015;44(3):20140285.
- Pakbaznejad Esmaeili E, Hurmerinta K, Rice D, Suomalainen A. Ultrasonographic localization of the thyroid gland for its optimal shielding prior to lateral cephalometric radiography: a pilot study. Dentomaxillofac Radiol. 2016;45(3):20150341.

- Choudhary AB, Motwani MB, Banode PJ, Chaudhary MB, Degwekar SS, Bhowate RR, Chaudhary SM. Utility of lead thyroid collar in cephalometric radiography. Indian J Dent Res. 2012 Sep-Oct;23(5):698-9.

- KP Sansare, V Khanna and F Karjodkar. Utility of thyroid collars in cephalometric radiography. Dentomaxillofac Radiol. 2011; 40:471-475.

\section{Diagnostic imaging for caries and periodontal disease}

Numerous studies (1-10) agree that visual examination, especially in primary dentition, is a key factor in assessing the presence or absence of dental caries. About this matter, some authors $(11,12)$ made an interesting distinction between dentitions that allow or prevent direct visualisation of interproximal contact areas. In fact, for the former type, it seems that radiographic analysis is not necessary to confirm diagnosis.

Regarding non-invasive diagnostic systems (13), the aid of fibre-optic transillumination (FOTI) may significantly favour the diagnostic process $(14,15)$.

"Ex ante" caries risk assessment of a patient (16-20, B) appears to be another discriminating factor in the diagnostic process of carious lesions in primary dentition. In fact, patients identified as at "high caries risk" shall be subject to a more "aggressive" diagnostic attitude with regard to the X-ray examinations to be carried out.

\section{Recommendation no. 1}

\section{The radiographic examination of choice for all patients suspected of having caries in primary teeth is a bitewing $X$-ray. This examination may be followed by an intraoral periapical image, if the patient is identified as "at high caries risk". Further radiographic examinations are not justified}

Strength of recommendation: A Degree of Evidence: I Assessment of carious processes in permanent teeth appears to be sufficiently supported by inspective clinical examinations, to be performed according to well-established criteria (17-20) and backed-particularly for high caries risk patients-in case there is clinical suspicion by a bitewing X-ray and, if necessary, by periapical images to be taken using image receptor holders and beam aiming appliances. 
Taking an X-ray, using the paralleling technique, of teeth with suspected caries lesions that may have jeopardised pulpal health is particularly indicated for high caries risk patients (21). It should be stressed that, in certain areas of the mouth, especially the upper and lower posterior areas, the superimposition of other bony structures might make it difficult to examine and outline the periapical image. Recent studies have pointed out that CBCT scans can highlight endodontium-originated periapical disease more accurately (22) than standard intraoral X-rays. This examination should, however, be limited to suspect or unclear cases, after traditional intraoral examination; CBCT examinations should not be considered as a first choice examination $(23, \mathrm{D})$.

At present, laser fluorescence and similar technologies (24-27) do not appear to be viable alternative solutions to $\mathrm{X}$-ray diagnostics, since they are not significantly supported by scientific evidence.

\section{Recommendation no. 2}

In all patients, when carious lesions of permanent teeth are suspected, the radiographic technique of choice is the bitewing. This image size is large enough to evaluate the whole crown of a permanent tooth. A second intraoral periapical X-ray should be taken in case of suspect infection involving the pulp or apex

Strength of recommendation: A Degree of Evidence: I Acute alveolar abscess is a rather common clinical condition; it is sometimes impossible to identify the infected tooth definitively.

In many cases, the patient's compliance may be limited, and clinical tests are often not nullifying (28).

Based on data from the literature (29), there are many diagnostic procedures that may be useful, from clinical to radiographic examination, by several imaging systems ranging from simple intraoral X-rays to more complex CBCT scans.

\section{Recommendation no. 3}

Swelling of the periapical tissues in primary or permanent dentition justifies intraoral X-ray examination, preferably using a dedicated film holder and beam aiming device. Examinations such as CBCT are not indicated in this diagnostic phase

Strength of recommendation: A Degree of Evidence: III If a fistula is present in the vestibular mucosa, close to the apex of either primary or permanent teeth, it should always raise suspicion of a septic lesion of the dental pulp also affecting the periapical tissues.

Intraoral X-ray, with the aid of a beam aiming device, is diagnostic investigation of choice. To more accurately assess the tooth the process originated from, it may be indicated to insert a gutta-percha cone in the fistula $(30,31)$.

\section{Recommendation no. 4}

If a fistula is present, diagnosis requires the intraoral radiograph to be taken with a gutta-percha cone inserted inside the fistula

Strength of recommendation: A Degree of Evidence: III Prepubertal patients with clear signs of periodontal disease should be examined through in-depth medical investigation and specific levels of supervision (32), especially in case differential diagnosis of acute septic processes of the periodontal structures is needed, or there is swelling of the marginal gingiva.

These signs sometimes appear similar to endodontically originated diseases (32-34).

\section{Recommendation no. 5}

X-ray examination of a permanent tooth showing infection signs on the marginal gingiva seems to be indicated, especially for patients with confirmed high risk of periodontal disease

Strength of recommendation: B Degree of Evidence: III Procedures such as direct pulp capping, apexogenesis, apecification and also complete root canal treatment require taking a preoperative X-ray with a paralleling system. This may give sufficient clues regarding the degree of maturity of the root apex and the estimated working length (35).

Clinicians are advised to be in possession of this image already in the diagnostic phase. It is worth remembering that, where cleaning and shaping of the endodontium are necessary in immature teeth, electronic apex locators are not reliable $(36,37)$. So, in case of doubt, a further intraoperative X-ray should be taken in such a way as to precisely confine all clinical manoeuvres within the endodontium.

Lastly, taking a post-operative intraoral X-ray to establish a reliable reference point for long-term follow-up of periapical reactive processes is indicated.

\section{Recommendation no. 6}

Taking intraoral radiograms with dedicated holders and beam aiming devices is indicated for partial or complete $\mathrm{RCT}$, pulp regeneration or canal shaping prior to root filling

Strength of recommendation: A Degree of Evidence: II For developing individuals, who were already treated for caries or trauma, checkups must follow if treatment included: 
- conservative treatment of a primary tooth;

- endodontic treatment of a primary tooth;

- conservative treatment (pulp capping) of a permanent tooth with an immature apex;

- conservative treatment (pulp capping) of a permanent tooth with a fully formed apex;

- endodontic treatment of a permanent tooth with an immature apex;

- endodontic treatment of a permanent tooth with a fully formed apex;

- treatment of intrusive or extrusive luxations;

- avulsion (assessment of the eruptive pathway of other teeth).

\section{Recommendation no. 7}

Intraoral X-ray is indicated for assessment, over time, of the periapical and pulp health conditions of permanent teeth that have undergone conservative treatment of the dental pulp. The follow-up images should be taken three months, six months, one year, since the end of therapy and then annually for the next three years

Strength of recommendation: A Degree of Evidence: II Based on findings from the literature, radiographic treatment longterm follow-up of primary teeth is deemed justifiable (38).

In case of septic or traumatic pathological processes leading to eradication or conservative (partial or complete) treatment of the pulp, a careful observation phase allows accurate assessment of positive or negative signs of the health conditions of the periapical tissues (38, A, B, C, D, E, F). On this subject, there are no studies indicating exact timing to mandatorily comply with for following checkups (34); there are, however, longitudinal studies about the assessment of healing processes of edodontically originated periapical lesions, in which patients were checked over time spans varying between six and twelve months, for the initial phases of treatment, and then once a year for a period from three to five years (35). As validating data is missing, it seemed appropriate to trust these deadlines for evaluation of such situations.

\section{Recommendation no. 8}

Intraoral X-ray is indicated for periapical health condition periodical assessment of mature or immature teeth after provisional endodontic therapy (apecification), pulp regeneration or definitive RCT. Radiographic follow-up is recommended after three and six months and then annually for the next three years, depending on the clinical situation

Strength of recommendation: A Degree of Evidence: II On the other hand, indications do emerge in checkup schedule to comply with, for assessing radiographic appearance of the pulp chamber and root canal-as well as of the apexof permanent teeth which, having undergone conservative pulp treatment (direct or indirect pulp capping/pulpotomy), must be regularly checked to avoid complications, such as obliteration of the root canal, or the onset of endodontically originated periapical lesions, in case partial or complete necrosis of the pulp occurs (34-36, A).

Clinicians should also keep track of problems that may arise in case the pulp disease justifies an endodontic treatment, although the tooth has not completed formation of the root apex, by performing an apexogenesis or apecification procedure which, based on scientific evidence, should be then supervised for a six months to three years time span (33).

\section{Bibliography}

- Pitts NB, Ekstrand KR, Foundation I. International Caries Detection and Assessment System (ICDAS) and its International Caries Classification and Management System (ICCMS) - methods for staging of the caries process and enabling dentists to manage caries. Community dentistry and oral epidemiology 2013;41(1):e41-52.

- Gimenez T, Piovesan C, Braga MM, Raggio DP, Deery C, Ricketts DN, et al. Visual Inspection for Caries Detection: A Systematic Review and Meta-analysis. Journal of dental research 2015;94(7):895-904.

- Gimenez T, Piovesan C, Braga MM, Raggio DP, Deery C, Ricketts DN, et al. Clinical relevance of studies on the accuracy of visual inspection for detecting caries lesions: a systematic review. Caries research 2015;49(2):91-98.

- Jallad M, Zero D, Eckert G, Ferreira Zandona A. In vitro Detection of Occlusal Caries on Permanent Teeth by a Visual, Light-Induced Fluorescence and Photothermal Radiometry and Modulated Luminescence Methods. Caries research 2015;49(5):523-530.

- Lino JR, Ramos-Jorge J, Coelho VS, Ramos-Jorge ML, Moyses MR, Ribeiro JC. Association and comparison between visual inspection and bitewing radiography for the detection of recurrent dental caries under restorations. International dental journal 2015;65(4):178-181.

- Ferraz EG, Silva LR, Sarmento VA, de Jesus Campos E, de Oliveira TF, Magalhaes JC, et al. Comparison of two visual methods for detecting caries among obese and non-obese children. Acta odontologica Scandinavia 2016;74(5):405-410.

- Freitas LA, Santos MT, Guare RO, Lussi A, Diniz MB. Association Between Visual Inspection, Caries Activity Status, and Radiography with Treatment Decisions on Approximal Caries in Primary Molars. Pediatric dentistry 2016;38(2):140-147. 
- Hoskin ER, Keenan AV. Can we trust visual methods alone for detecting caries in teeth? Evidence-based dentistry 2016;17(2):41-42.

- Melo M, Pascual A, Camps I, Del Campo A, Ata-Ali J. Caries diagnosis using light fluorescence devices in comparison with traditional visual and tactile evaluation: a prospective study in 152 patients. Odontology 2016.

- Terry GL, Noujeim M, Langlais RP, Moore WS, Prihoda TJ. A clinical comparison of extraoral panoramic and intraoral radiographic modalities for detecting proximal caries and visualizing open posterior interproximal contacts. Dento maxillo facial radiology 2016;45(4):20150159.

- Theocharopoulou A, Lagerweij MD, van Strijp AJ. Use of the ICDAS system and two fluorescence-based intraoral devices for examination of occlusal surfaces. European journal of paediatric dentistry: official journal of European Academy of Paediatric Dentistry 2015;16(1):51-55.

- Twetman S. Visual Inspection Displays Good Accuracy for Detecting Caries Lesions. The journal of evidencebased dental practice 2015;15(4):182-184.

- Castilho LS, Cotta FV, Bueno AC, Moreira AN, Ferreira EF, Magalhaes CS. Validation of DIAGNOdent laser fluorescence and the International Caries Detection and Assessment System (ICDAS) in diagnosis of occlusal caries in permanent teeth: an in vivo study. European journal of oral sciences 2016;124(2):188-194.

- Pretty IA, Ekstrand KR. Detection and monitoring of early caries lesions: a review. European archives of paediatric dentistry: official journal of the European Academy of Paediatric Dentistry 2016;17(1):13-25.

- Bussaneli DG, Restrepo M, Boldieri T, Pretel H, Mancini MW, Santos-Pinto L, et al. Assessment of a new infrared laser transillumination technology $(808 \mathrm{~nm})$ for the detection of occlusal caries-an in vitro study. Lasers in medical science 2015;30(7):1873-1879.

- Kuhnisch J, Sochtig F, Pitchika V, Laubender R, Neuhaus $\mathrm{KW}$, Lussi A, et al. In vivo validation of near- infrared light transillumination for interproximal dentin caries detection. Clinical oral investigations 2016;20(4):821829.

- Tellez M, Gomez J, Pretty I, Ellwood R, Ismail AI. Evidence on existing caries risk assessment systems: are they predictive of future caries? Community dentistry and oral epidemiology 2013;41 (1):67-78.

- Gauba K, Goyal A, Mittal N. A Cambra. Model For High Caries Risk Indian Children: A Pragmatic Comprehensive Tailored Intervention. The Journal of clinical pediatric dentistry 2016;40(1):36-43.

- Goolsby SP, Young DA, Chiang HK, Carrico CK, Jackson LV, Rechmann P. The Effects of Faculty Calibration on Caries Risk Assessment and Quality Assurance. Journal of dental education 2016;80(11):1294-1300.

- Mills C, Patel P. Adopting caries risk assessment in all practice environments. General dentistry 2016;64(4):6672.

- Sudhir KM, Kanupuru KK, Fareed N, Mahesh P, Vandana K, Chaitra NT. CAMBRA as a Tool for Caries Risk Prediction Among 12- to 13-year-old Institutionalised Children-A Longitudinal Follow-up Study. Oral health \& preventive dentistry 2016;14(4):355-362.

- American Academy of Pediatric Dentistry. Ad Hoc Committee on Pedodontic R. Guideline on prescribing dental radiographs for infants, children, adolescents, and persons with special health care needs. Pediatric dentistry 2012;34(5):189-191.

- Spin-Neto R, Gotfredsen E, Wenzel A. Impact of voxel size variation on CBCT-based diagnostic outcome in dentistry: a systematic review. Journal of digital imaging 2013;26(4):813-820.

- Jacobs R. Dental cone beam CT and its justified use in oral health care. JBR-BTR: organe de la Societe royale belge de radiologie 2011;94(5):254-265.

- Mendes FM, Novaes TF, Matos R, Bittar DG, Piovesan C, Gimenez T, et al. Radiographic and laser fluorescence methods have no benefits for detecting caries in primary teeth. Caries research 2012;46(6):536-543.

- Krzyzostaniak J, Kulczyk T, Czarnecka B, Surdacka A. A comparative study of the diagnostic accuracy of cone beam computed tomography and intraoral radiographic modalities for the detection of noncavitated caries. Clinical oral investigations 2015;19(3):667-672.

- Jablonski-Momeni A, Heinzel-Gutenbrunner M, Vill G. Use of a fluorescence-based camera for monitoring occlusal surfaces of primary and permanent teeth. International journal of paediatric dentistry 2016;26(6):448456.

- Roberts JF, Curzon ME, Koch G, Martens LC. Review: behaviour management techniques in paediatric dentistry. European archives of paediatric dentistry: official journal of the European Academy of Paediatric Dentistry 2010;11(4):166-174.

- Mejare IA, Axelsson S, Davidson T, Frisk F, Hakeberg M, Kvist T, et al. Diagnosis of the condition of the dental pulp: a systematic review. International endodontic journal 2012;45(7):597-613.

- American Academy on Pediatric Dentistry Ad Hoc Committee on Pedodontic R, American Academy on Pediatric Dentistry Council on Clinical A. Guideline on prescribing dental radiographs for infants, children, adolescents, and persons with special health care needs. Pediatric dentistry 2008;30(7 Suppl):236-237.

- Kanagasingam S, Mannocci F, Lim CX, Yong CP, Patel S. Diagnostic accuracy of periapical radiography and 
cone beam computed tomography in detecting apical periodontitis using histopathological findings as a reference standard. Int Endod J. 2016 Apr 11. https://doi. org/10.1111/iej.12650. [Epub ahead of print].

- Nibali L, Farias BC, Vajgel A, Tu YK, Donos N. Tooth loss in aggressive periodontitis: a systematic review. $\mathrm{J}$ Dent Res. 2013 Oct;92(10):868-75.

- McCabe PS, Dummer PM. Pulp canal obliteration: an endodontic diagnosis and treatment challenge. International endodontic journal 2012;45(2):177-197.

- Zero DT, Zandona AF, Vail MM, Spolnik KJ. Dental caries and pulpal disease. Dental clinics of North America 2011;55(1):29-46.

- Harlamb SC. Management of incompletely developed teeth requiring root canal treatment. Australian dental journal 2016;61 Suppl 1:95-106.

- Kim YJ, Chandler NP. Determination of working length for teeth with wide or immature apices: a review. International endodontic journal 2013;46(6):483-491.

- Kuhnisch J, Ekstrand KR, Pretty I, Twetman S, van Loveren C, Gizani S, et al. Best clinical practice guidance for management of early caries lesions in children and young adults: an EAPD policy document. European archives of paediatric dentistry: official journal of the European Academy of Paediatric Dentistry 2016;17(1):3-12.

- Kullman L, Al Sane M. Guidelines for dental radiography immediately after a dentoalveolar trauma, a systematic literature review. Dental traumatology: official publication of International Association for Dental Traumatology 2012;28(3):193-199.

\section{Webliography}

A http://dentaltraumaguide.org.

B http://www.aapd.org/media/PoliciesGuidelines/GCari esRiskAssessment7.pdf.

C http://www.aapd.org/media/PoliciesGuidelines/G-Pulp1 .pdf.

D http://www.aapd.org/media/PoliciesGuidelines/ERadi ographs1.pdf.

E http://www.aapd.org/media/PoliciesGuidelines/EFrac tures1.pdf.

F http://www.aapd.org/media/PoliciesGuidelines/EInju ries2.pdf.

\section{Diagnostic imaging in orthodontics and gnathology}

In orthodontics, radiographic examination is needed in case dental anomalies are found upon clinical examination or when orthodontic, corrective or interceptive, treatment is needed. ${ }^{1}$
The timing of the first radiographic examination should not be based on the patient's age, but on each developing individual's specific clinical needs. Since every patient is unique, the need for dental X-rays can only be determined upon the analysis of his medical and dental history, and of his clinical condition and after assessing exposure to environmental risk factors that could jeopardise oral health.

$\mathrm{X}$-ray should only be used as a diagnostic examination when considered useful for the patient's health, and when it may provide additional information helpful for treatment, complying with the "principle of justification". Given the importance and the current relevance of this issue, numerous guidelines have been published. ${ }^{1-7}$ These studies unanimously agree that prescribing X-ray examinations is solely advisable as necessary. In compliance with all the international guidelines, ${ }^{1-7}$ this section will describe indications and levels of evidence for each type of radiographic examination suitable for identifying disease, also concerning the cost-benefit ratio.

For the orthodontic patient, radiographic examination generally consists of panoramic radiography, i.e. orthopantomography (OPT), and latero-lateral teleradiography of the head, which may be supplemented, in the most complex cases, by more specific examinations.

OPT allows assessing the presence or agenesis of permanent teeth, the position of teeth yet to erupt, and any supernumerary teeth. ${ }^{8}$ It is not, however, advisable for evaluating caries in patients suffering from dental decay about to undergo orthodontic treatment. In such cases, in fact, a bitewing image is to be preferred. ${ }^{9}$

Teleradiography of the head and cephalometric analysis are indicated for orthodontic diagnosis, treatment planning and the monitoring of results following therapy on the maxillo-mandibular bony structure. A useful aid in choosing the appropriate age to prescribe this radiographic examination is the Index of Orthodontic Treatment Need (IOTN). ${ }^{10}$ This index allows objective distinction between severe cases requiring early treatment (IOTN 4 and IOTN 5) and cases which treatment may begin by the age of $10-11 .{ }^{11}$

The use of teleradiography for PA projection for facial asymmetries must be carried out with great care, considering the difficulty in locating the cephalometric points in this projection. ${ }^{12,13}$ Moreover, it should be kept in mind that even slight rotations of the head in the cephalostat might mask the presence of facial asymmetry. ${ }^{12,14}$ Cone beam computed tomography (CBCT) guarantees the volumetric graphic 3D representation of all anatomical bony structures, as well as overcoming the limitations of ordinary $2 \mathrm{D}$ radiographic images-i.e. geometric distortion and superimposition of bony and dental structures, and improper positioning of the patient's head in the cephalostat ${ }^{15}$ - since usual practice continues to favour $2 \mathrm{D}$, even though $3 \mathrm{D}^{16}$ cephalometric analyses do exist. 
Routine prescription of this examination for young patients is considerably limited, by both the literature and all the existing guidelines, ${ }^{15,17}$ upon radiation dose, to individual clinical cases. It should be highlighted, though, that it is current common practice among orthodontists to convert 3D images into 2D, for cephalometric analysis. ${ }^{15,17}$ In all cases, choosing the FOV is crucial when prescribing this examination, in order not to expose the patient to a non-optimised radiation dose with an acquisition field too extensive for the target zone. Small and medium FOVs are preferable to large ones. In orthodontics, small and medium FOVs are indicated for the assessment of impacted teeth, root resorption caused by impacted teeth, and the designated area for mini-screw insertion in patients with malocclusion. ${ }^{14,18-20}$ Moreover, successful application of mini-implants is influenced by $\mathrm{CBCT}^{14}$ evaluation of bone density, as it reduces the risk of screw detachment. The use of large FOVs may be indicated in complex orthodontic cases, or severe craniofacial dysmorphoses $^{21,22}$ (IOTN 5), i.e. of cleft lip-palate, syndromes, facial asymmetries ${ }^{23}$, etc., or, anyway, patients candidate for major oral or maxillofacial surgery. In all these cases, with one single exposure, despite the higher radiation dose being used, the orthodontist and the oral and maxillofacial surgeons get access all the required information.

The use of large FOVs for a 3D cephalometric examination in simple clinical cases is not validated by the literature, nor by existing guidelines. ${ }^{1-7}$

Temporomandibular disorders (TMD) affect the temporomandibular joint (TMJ), the masticatory muscles and associated structures. The wide sign and symptom range of these disorders includes pain, joint noise and irregular or limited mandibular function. In a recent update, the American Academy of Orofacial Pain divided TMDs into two large categories: TMJ disorders and masticatory muscle disorders. ${ }^{24}$

The prevalence of TMD in newborns, children and teenagers is highly variable in the literature, inasmuch as data between 6 and $68 \%$ are reported. These diverse percentages may originate from the different analysed samples, the diagnostic criteria and examination techniques. The prevalence of signs and symptoms, however, as supported by important scientific evidence, ${ }^{25-33}$ increases with age.

Among the most frequently found TMJ disorders in paediatric age, we may list:

- internal derangement (displacement of the articular disc with or without reduction);

- inflammatory disorders (e.g. sinovitis, capsulitis);

- ankylosis;

- arthritis;

- fractures, condylar hypoplasia and hyperplasia.

Diagnosis of TMDs is based on a combination of anamnestic, clinical and radiological information about the TMJ.
Radiological examination is only indicated when insufficient information is obtained from the anamnestic-clinical examinations. ${ }^{24,34}$ Different radiological techniques are employed in study of the TMJ, with different sensitivities, specificity and appropriateness in relation to the diagnostic question. Magnetic resonance (MR) and computed tomography (CT) and/or CBCT scanning should be preferred over conventional radiography.

$\mathrm{CT}$ is held to be the gold standard imaging technique for bone lesion assessment, while MRI is considered the gold standard for ligament and articular capsule structure analysis. ${ }^{24,34}$

\section{Recommendation no. 1}

For a correct orthodontic diagnosis and treatment planning, a panoramic radiography and a teleradiography are necessary

Strength of recommendation: A Degree of Evidence: I Teleradiography of the skull in norma lateralis, panoramic radiography and radiography of the non-dominant hand and wrist should be prescribed based on the degree of malocclusion (IOTN) ${ }^{10}$ and the patient's age. ${ }^{1-7}$ Frequent radiographic checkups to monitor progress of therapy are advised against and inappropriate, unless there is a precise clinical indication.

In case of serious craniofacial dysmorphoses or of skeletal III class, orthodontic treatment will begin early, getting radiographic records of the patient is advisable at an early stage. It should be highlighted that if a CBCT scan of a patient with severe dysmorphosis is taken, then the standard orthodontic radiographic examinations should not be prescribed, as the same images may be obtained from the CBCT file itself.

\section{Recommendation no. 2}

\section{Limit prescription of $C B C T$ and, preferably, use small and medium FOVs}

Strength of recommendation: A Degree of Evidence: I In the past decade, a considerable increase in the use of CBCT in dentistry, especially in orthodontics, was witnessed. This happened because from one single CBCT scan, we can obtain all the radiographic images for orthodontic diagnosis. Nonetheless, numerous recent guidelines and studies have drastically limited prescription of CBCT to selected clinical cases.

CBCT is therefore indicated for diagnosis and treatment planning for severe dysmorphoses-craniofacial syndromes, impacted teeth, bone anomalies, serious facial asymmetries and condylar aplasia or hypoplasia. ${ }^{1-7}$ 


\section{Recommendation no. 3}

The use of CBCT for cephalometric diagnosis in orthodontic patients with moderate-light malocclusion is strongly discouraged

Strength of recommendation: A Degree of Evidence: I Taking a CBCT scan, and therefore subjecting the patient to high radiation doses, to only use the latero-lateral and the panoramic projections, is inappropriate in terms of cost/benefit ratio, nor does it guarantee the patient's health. ${ }^{1-7}$ The same information may be obtained by techniques requiring a lower radiation dose.

$\mathrm{CBCT}$ scanning is justified as further examination, when inclination of the canines on the panoramic image exceeds $30^{\circ}$, or when root resorption of one of the adjacent teeth is suspected..$^{35}$

\section{Recommendation no. 4}

Posterior-anterior teleradiography, with related cephalometric analysis, requires a highly experienced clinician

\section{Strength of recommendation: A Degree of Evidence:} I Cephalometric analysis of the posterior-anterior teleradiograph, compared to the latero-lateral analysis, requires the clinician to have extensive experience, as localisation of the cephalometric points is far more complex due to bone superimpositions. Moreover, the positioning of the patient's head may heavily influence the diagnosis, such as the presence of an asymmetry. ${ }^{12,13}$ If a CBCT scan was already taken, in accordance with the previous recommendations, the mirroring technique of the bony structures of the splanchnocranium ${ }^{23}$ may supplement data from the posterior-anterior, allowing a simulation of the treatment plan.

\section{Recommendation no. 5}

For TMJ ligament-capsule tissue disorders, an MRI is recommended. For TMJ bone disease, a CBCT or a CT scan prescription is indicated. The OPT is of no diagnostic use in these cases

Strength of recommendation: A Degree of Evidence: I MRI of the TMJ should be used in case an internal derangement of the TMJ disc is suspected, while CBCT or CT scan is used in those clinical cases suspected of condyle and glenoid cavity involvement based on medical history and clinical examination. Panoramic and other radiographic images (e.g. stratigraphy of TMJ and CBCT) do not supply information about the joint components and ligament-capsule components (disc). They are insufficient for assessment of the bony structures (condyle and glenoid cavity) and may reproduce the condyle-glenoid cavity relationships unreliably, due to projection errors bound to the imaging technique. $^{24,34}$

\section{Bibliography}

- K. Isaacson AT, N. Atack, K. Horner, E. Whaites. Guidelines for the use of radiographs in clinical orthodontics. British Orthodontic Society 2015.

- Guideline on prescribing dental radiographs for infants, children, adolescents, and persons with special health care needs. Pediatr Dent 2012;34:189-191.

- Dula K, Bornstein MM, Buser D, Dagassan-Berndt D, Ettlin DA, Filippi A et al. SADMFR guidelines for the use of Cone-Beam Computed Tomography/Digital Volume Tomography. Swiss Dent J 2014;124:1169-1183.

- Clinical recommendations regarding use of cone beam computed tomography in orthodontics. [corrected]. Position statement by the American Academy of Oral and Maxillofacial Radiology. Oral Surg Oral Med Oral Pathol Oral Radiol 2013;116:238-257.

- Association AD. Dental radiographic examination: recommendation for patient selection and limiting radiation exposure. U.S. DEPARTMENT OF HEALTH AND HUMAN SERVICES Public Health Service Food and Drug Administration 2012.

- DENTISTRY AAOP. Guideline on Prescribing Dental Radiographs for Infants, Children, Adolescents, and Persons with Special Health Care Needs. ENDORSEMENTS 2012;37.

- Radiology AAoOaM. Clinical recommendations regarding use of cone beam computed tomography in orthodontics. Position statement by the American Academy of Oral and Maxillofacial Radiology. ORAL AND MAXILLOFACIAL RADIOLOGY 2013;116:238-257.

- Pakbaznejad Esmaeili E, Ekholm M, Haukka J, WaltimoSirén J. Quality assessment of orthodontic radiography in children. The European Journal of Orthodontics 2015.

- Kamburoglu K. Re: Evaluation of root resorption following rapid maxillary expansion using cone-beam computed tomography. Angle Orthod. 2011 Aug 15. [Epub ahead of print]. https://doi.org/10.2319/060411-367.1

- By Asli Baysal, Irfan Karadede, Seyit Hekimoglu, Faruk Ucar, Torun Ozer, Ilknur Veli, Tancan Uysal. Angle Orthod 2012;82:181.

- Grzywacz I. [Orthodontic treatment needs and indications assessed with IOTN]. Ann Acad Med Stetin 2004;50:115-122.

- Dinger B, Yetkiner E, Aras I, Attin T, Attin R. Influence of lateral cephalometric radiographs on extraction deci- 
sion in skeletal class I patients. Head \& Face Medicine 2013;9:36-36.

- Leonardi R, Annunziata A, Caltabiano M. Landmark identification error in posteroanterior cephalometric radiography. A systematic review. Angle Orthod 2008;78:761-765.

- Tai B, Goonewardene MS, Murray K, Koong B, Islam SM. The reliability of using postero-anterior cephalometry and cone-beam CT to determine transverse dimensions in clinical practice. Aust Orthod J 2014;30:132142.

- Cook JT. Asymmetry of the cranio-facial skeleton. Br J Orthod 1980;7:33-38.

- Kapila SD, Nervina JM. CBCT in orthodontics: assessment of treatment outcomes and indications for its use. Dentomaxillofac Radiol 2015;44:20140282.

- Farronato G, Farronato D, Toma L, Bellincioni F. A synthetic three-dimensional craniofacial analysis. J Clin Orthod 2010;44:673-678; quiz 688.

- Kapila S, Conley RS, Harrell WE, Jr. The current status of cone beam computed tomography imaging in orthodontics. Dentomaxillofac Radiol 2011;40:24-34.

- Botticelli S, Verna C, Cattaneo PM, Heidmann J, Melsen B. Two- versus three-dimensional imaging in subjects with unerupted maxillary canines. The European Journal of Orthodontics 2011;33:344-349.

- Naoumova J, Kjellberg H, Palm R. Cone-beam computed tomography for assessment of palatal displaced canine position: a methodological study. Angle Orthod 2014;84:459-466.

- Lai RF, Zou H, Kong WD, Lin W. Applied anatomic site study of palatal anchorage implants using cone beam computed tomography. Int J Oral Sci 2010;2:98-104.

- Celikoglu M, Buyuk SK, Sekerci AE, Cantekin K, Candirli C. Maxillary dental anomalies in patients with cleft lip and palate: a cone beam computed tomography study. J Clin Pediatr Dent 2015;39:183-186.

- Ternovoi SK, Serova NS, Ivanova DV. [Radiodiagnostic methods for dental anomalities]. Vestnik rentgenologii i radiologii 2012:4-7.

- Damstra J, Oosterkamp BC, Jansma J, Ren Y. Combined 3-dimensional and mirror-image analysis for the diagnosis of asymmetry. Am J Orthod Dentofacial Orthop 2011;140:886-894.

- Schiffman E, Ohrbach R, Truelove E, Look J, Anderson G, Goulet JP et al. Diagnostic Criteria for Temporomandibular Disorders (DC/TMD) for Clinical and Research Applications: recommendations of the International
RDC/TMD Consortium Network* and Orofacial Pain Special Interest Groupdagger. J Oral Facial Pain Headache 2014;28:6-27.

- LeResche L. Epidemiology of temporomandibular disorders: implications for the investigation of etiologic factors. Crit Rev Oral Biol Med 1997;8:291-305.

- Magnusson T, Egermark-Eriksson I, Carlsson GE. Fouryear longitudinal study of mandibular dysfunction in children. Community Dent Oral Epidemiol 1985;13:117120.

- Mohlin B, Pilley JR, Shaw WC. A survey of craniomandibular disorders in 1000 12-year-olds. Study design and baseline data in a follow-up study. Eur J Orthod 1991;13:111-123.

- Nielsen L, Melsen B, Terp S. Clinical classification of 14-16-year-old Danish children according to functional status of the masticatory system. Community Dent Oral Epidemiol 1988;16:47-51.

- Pahkala R, Laine T, Narhi M, Ettala-Ylitalo UM. Relationship between craniomandibular dysfunction and pattern of speech sound production in a series of firstgraders. Eur J Orthod 1991;13:378-385.

- Torii K. Longitudinal course of temporomandibular joint sounds in Japanese children and adolescents. Head Face Med 2011;7:17.

- Widmalm SE, Christiansen RL, Gunn SM, Hawley LM. Prevalence of signs and symptoms of craniomandibular disorders and orofacial parafunction in 4-6-year-old African-American and Caucasian children. J Oral Rehabil 1995;22:87-93.

- Allori AC, Chang CC, Farina R, Grayson BH, Warren SM, McCarthy JG. Current concepts in pediatric temporomandibular joint disorders: Part 1. Etiology, epidemiology, and classification. Plast Reconstr Surg 2010;126:1263-1275.

- Feteih RM. Signs and symptoms of temporomandibular disorders and oral parafunctions in urban Saudi Arabian adolescents: a research report. Head Face Med 2006;2:25.

- AAoPD CAC-TJPiCS. Guideline on Acquired Temporomandibular Disorders in Infants, Children, and Adolescents. Pediatric dentistry Sept-Oct 2015;37(5):78-84.

- Guarnieri R, Cavallini C, Vernucci R, Vichi M, Leonardi $\mathrm{R}$, Barbato E. Impacted maxillary canines and root resorption of adjacent teeth: A retrospective observational study. Med Oral Patol Oral Cir Bucal 2016;21:e743-e750. 


\section{Diagnostic imaging in cranio-maxillofacial malformations}

A vast number of alteration related diseases of both embryonic and acquired origin come under these headings. Craniosynostoses and craniofacial stenoses, as well as orofacial clefts and branchial arch syndromes, are an example.

Since we are dealing with deformations that are often present at birth, radiographic investigations should be proportionate to the diagnostic and therapeutic objectives of the single case. ${ }^{6,13}$

The golden rule is that radiographic investigations should be carried out only when they are essential to diagnosis and treatment planning. ${ }^{6,13,14}$

By way of example, the diagnosis of skull malformations and of cranial suture anomalies is purely clinical. $3,13,14,15$ Direct X-ray imaging is not indicated as a routine examination, since the same information may be obtained by ultrasound imaging. ${ }^{2,5,15,24}$ Multislice computer tomography (MSCT) or CBCT is indicated in selected cases, when necessary for treatment planning. ${ }^{15,22}$

MSCT and CBCT are not indicated as a routine examination for cleft lip and palate, since their diagnosis is clinical. These are only indicated when necessary for treatment planning. ${ }^{3,12}$ MSCT or CBCT is also not indicated as a routine examination for skeletal facial deformities involving bone and/or soft tissues, but may be used for treatment planning. ${ }^{3}$

\section{Recommendation no. 1}

\section{Diagnosis of cleft lip and palate is strictly clinical}

Strength of recommendation: A Degree of Evidence: I A CT examination is indicated for treatment planning. $2,10,11,12,16$

CT often requires sedation of the patient.

\section{Recommendation no. 2}

\section{Diagnosis of craniostenosis is strictly clinical, $4,14,15,18,21$ but CT may be of assistance ${ }^{23}$}

Strength of recommendation: A Degree of Evidence: II For treatment planning, a CT examination is indicated. ${ }^{5,14,23}$ For suspected anomalies of the cranial sutures and the anterior fontanelle, an ultrasound examination is often sufficient. ${ }^{2,5,15,24}$

\section{Recommendation no. 3}

MSCT or CBCT may be indicated for analysis of I and II branchial arch syndromes craniofacial defects and with the purpose of treatment planning. $1,7,8,14,15,17,18,20$

Strength of recommendation: A Degree of Evidence: II In cranio-maxillofacial defects, CBCT may be indicated as an investigation alternative to $\mathrm{MSCT},{ }^{2,24}$ since the radiation dose, based on scientific evidence, is lower where evaluation of the soft tissues is not required. ${ }^{3,6,9,19,23}$

\section{Bibliography}

- Adam M. Alessio, Grace S. Phillips. A pediatric CT dose estimator. Pediatric Radiol 2010; 40:1816-1821.

- Anderson PJ, Yong R, Surman TL, Rajion ZA, Ranjitkar. Application of three-dimensional computed tomography in craniofacial clinical practice and research. Australian Dental Journal 2014; 59 (174-185).

- Boeddinghaus R, Whyte A/European Journal of Radiology 66 (2008) 396-418.

- Cabrera-Martos I et al. Clinical profile and evolution of infants with deformational plagiocephaly included in a conservative treatment program. Childs Nerv Syst. 2013 Oct;29(10):1893-8.

- Chaitra A. Badve, Mallikarjunappa MK, Ramesh S. Iyer, Gisele E. Ishak, Paritosh C. Khanna. Craniosynostosis: imaging review and primer on computed tomography. Pediatric Radiology 2013; 43; 728-742.

- European Commission. Radiation Protection no 172. Cone Beam CT for dental and maxillofacial radiology (Evidence-based guidelines), 2012.

- Evans KN et al. Robin sequence: from diagnosis to development of an effective management plan. Pediatrics. 2011 May;127(5):936-48.

- Gonik NJ, Cheng J, Lesser M, Shikowitz MJ, Smith LP. Patient selection in congenital pyriform aperture stenosis repair-14 year experience and systematic review of literature. Int J Pediatr Otorhinolaryngol. 2015 Feb;79(2):235-9.

- Khursheed A, Hillier MC, Shrimpton PC et al. Influence of patient age on normalized effective doses calculated for CT examinations. Br J Radiol 2002; 75:819_ 830.

- Klatt J, Heiland M, Blessmann M, Blake F, Schmelzle $\mathrm{R}$, Pohlenz P. Clinical indication for intraoperative 3D imaging during open reduction of fractures of the neck and head of the mandibular condyle. J Craniomaxillofac Surg. 2011 Jun;39(4):244-8. 
- Kolar JC. An epidemiological study of nonsyndromal craniosynostoses. J Craniofac Surg. 2011 Jan;22(1):479.

- Kuijpers MAR, Chiu Y-T, Nada RM, Carels CEL, Fudalej PS (2014) Three-dimensional Imaging Methods for Quantitative Analysis of Facial Soft Tissues and Skeletal Morphology in Patients with Orofacial Clefts: A Systematic Review. PLoS ONE 9(4): e93442.

- Lebuis A, Bortoluzzi P, Huynh N, Bach N. Occlusal Relations in Patients With Scaphocephaly. J Craniofac Surg. 2015 Sep;26(6):1893-9.

- Looman WS, Flannery AB. Evidence-based care of the child with deformational plagiocephaly, Part I: assessment and diagnosis. J Pediatr Health Care. 2012 JulAug;26(4):242-50.

- McCarthy JG et al. Craniosynostosis Working Group. Parameters of care for craniosynostosis. Cleft Palate Craniofac J. 2012 Jan;49 Suppl:1S-24S.

- McIlvaine E. et al. Apriori feasibility testing of randomized clinical trial design in patients with cleft deformities and Class III malocclusion. Int J Pediatr Otorhinolaryngol. 2014 May;78(5):725-30.

- Pluijmers BI, Caron CJ, Dunaway DJ, Wolvius EB, Koudstaal MJ. Mandibular reconstruction in the growing patient with unilateral craniofacial microsomia: a systematic review. Int J Oral Maxillofac Surg. 2014 Mar;43(3):286-95.

- Sauerhammer TM et al. Combined metopic and unilateral coronal synostoses: a phenotypic conundrum. J Craniofac Surg. 2014 Mar;25(2):437-40.

- Scarfe WF, Li Z, Aboelmaaty W, Scott SA, Farman AG. Maxillofacial cone beam computed tomography: essence, elements and steps to interpretation. Australian Dental Journal 2012; 57; 46-60.

- Sun Z et al. Multidetector computerized tomographic fistulography in the evaluation of congenital branchial cleft fistulae and sinuses. Oral Surg Oral Med Oral Pathol Oral Radiol. 2012 May;113(5):688-94.

- Tonni G, Panteghini M, Rossi A, Baldi M, Magnani C, Ferrari B, Lituania M. Craniosynostosis: prenatal diagnosis by means of ultrasound and SSSE-MRI. Family series with report of neurodevelopmental outcome and review of the literature. Arch Gynecol Obstet. 2011 Apr;283(4):909-16.

- Vazquez JL, Pombar MA, Pumar JM, del Campo VM. Optimised low-dose multidetector CT protocol for children with cranial deformity. Eur Radiol (2013) 23:22792287.

- Wery MF et al. Three-dimensional computed tomographic evaluation of Le Fort III distraction osteogenesis with an external device in syndromic craniosynostosis. Br J Oral Maxillofac Surg. 2015 Mar;53(3):285-91.
- Yin H, Dong X, Yang B. A new three-dimensional measurement in evaluating the cranial asymmetry caused by craniosynostosis. Surg Radiol Anat. 2015 Oct;37(8):98995.

\section{Diagnostic imaging in dental anomalies}

\section{TOOTH IMPACTION.}

An impacted tooth is one that, somehow, fails to erupt in the oral cavity within the expected developmental window. ${ }^{1}$ An impacted tooth may also be defined as a tooth, which is partially or not erupted, showing clinical, anatomical and radiological signs that suggest its correct eruption is unlikely. $^{2}$

Dental impaction is a common problem (25-50\% of the world population), which prevalence is strongly related to age, gender, ethnicity and anatomical localisation (quadrants), ${ }^{3,4}$ while its incidence appears to be increasing. ${ }^{5}$

The teeth of normal permanent dentition that are most often impacted are, in order of frequency, third molars, upper canines, premolars, and upper central incisors. ${ }^{6}$ In Europe, impaction of third molars is observed in more than $70 \%$ of young adults, ${ }^{7}$ and extraction of third molars is the most frequent procedure in oral surgery.

Possible causes of dental impaction are lack of space, position anomalies, supernumerary teeth, persistence of primary teeth, odontogenic cysts/tumours, trauma and systemic diseases. Among the causes above listed, the first two are the most frequent. $^{8}$

\section{Recommendation no. 1}

\section{On suspicion of dental impaction, level I radiological examination must not be carried out before the age of 6}

Strength of recommendation A Degree of Evidence I At 6 years of age, permanent tooth buds, except those of the III molars, are visible in the panoramic image, a level I radiographic investigation. However, before prescribing a radiographic examination for suspected impaction, the patient's medical history (e.g. positive family medical history for dental impaction) should be taken into consideration, together with the patient's clinical signs and symptoms (e.g. unexpected missing teeth, eruption anomaly, "bulging" of the gingival mucosa) and the risk/benefit ratio in exposing the patient to a potentially harmful radiological examination (exposure to ionising radiations). ${ }^{2-7}$ 


\section{Recommendation no. 2}

On suspicion of dental impaction, orthopantomography should be the first diagnostic examination

\section{Strength of recommendation A Degree of Evidence} IV Orthopantomography is the $2 \mathrm{D}$ radiological imaging technique recommended for the initial assessment of dental impaction. This image provides information on the position of the impacted tooth, its relationship with the alveolar ridge, its projective relationships with the adjacent teeth and structures and the presence of any associated lesions (radiotransparent and/or radio-opaque periradicular lesions). ${ }^{12}$ However, 2D imaging techniques turn out to be less accurate in assessing dental impaction than 3D CBCT. In particular, it should be remembered that $2 \mathrm{D}$ imaging is significantly inferior to $3 \mathrm{D}$ in assessing relationships between the impacted tooth and the adjacent teeth and critical structures (e.g. the mandibular canal, the nasal fossa and the maxillary sinus). ${ }^{13}$

There is no clinical evidence supporting the use of CBCT as an initial diagnostic examination of dental impaction. The use of this technique must be restricted to cases for which level I radiographic investigations cannot provide adequate information.

\section{Recommendation no. 3}

Level I radiographic investigations are an efficient tool in defining the risk of injuring the alveolar nerve and, in non-critical cases, may be considered sufficient in treatment planning for the extraction of a III lower molar

Strength of recommendation A Degree of Evidence IV With reference to impaction of the third lower molars, orthopantomography, and, in some cases, intraoral radiography, is an efficient imaging technique for estimating the risk of injuring the lower alveolar nerve. ${ }^{14,15}$ So, if level I radiographic investigations exclude any chance contact between the III lower molar and the mandibular canals, 2D imaging may be held to be sufficient and 3D CBCT imaging unnecessary. ${ }^{16,18}$

\section{Recommendation no. 4}

Panoramic imaging may be appropriate for assessment III upper molar impaction and its treatment planning

Strength of recommendation B Degree of Evidence IV With reference to impaction of the third upper molar, orthopantomography may be solely considered sufficient (i.e. CBCT scan would not be necessary) in case panoramic 2D imaging provides adequate information on the position of the impacted tooth and its relationship with adjacent anatomical structures, especially with the maxillary sinus floor. ${ }^{19,21}$

\section{Recommendation no. 5}

Level I radiographic investigations are not deemed to be an adequate imaging technique for identification and characterisation of external root resorption

Strength of recommendation: A Degree of Evidence: IV Level I radiographic investigations (panoramic and intraoral X-ray) are the most commonly used imaging techniques for identification and localisation of dental impaction. Nevertheless, accurate localisation of the impacted tooth and its relationships with adjacent structures are required for a correct treatment planning. In particular, identifying and evaluating the extent of an external root resorption process-sometimes observed in dental impaction, especially in the upper canines-require a $3 \mathrm{D}$ evaluation. ${ }^{22,24}$ So, on suspicion of external root resorption associated with dental impaction, a 3D CBCT imaging technique is indicated. ${ }^{22,25}$

\section{Recommendation no. 6}

Periapical intraoral imaging may be used for dental impaction of the upper incisor-canine region

Strength of recommendation: B Degree of Evidence: IV Periapical radiography is an imaging technique generally used in dentistry to evaluate periapical lesions, root morphology (when planning extraction/endodontic treatment) and post-implant surgery checkup. In assessing dental impaction in the upper incisor-canine area, given its restricted anatomical vision, a periapical image can play a role, albeit limited, in evaluating tooth position and relationship with adjacent structures.

\section{Recommendation no. 7}

CBCT is an essential imaging technique in assessing the relationship between third lower molars, mandibular canal and the surrounding anatomical structures, and, similarly, those between third upper molars and the maxillary sinus floor

Strength of recommendation: A Degree of Evidence: IV CBCT is the imaging technique indicated for assessing the relationship between the roots of third molars and the mandibular canal, in case the panoramic image suggests contact with the canal itself and, therefore, risk of injury of the lower alveolar nerve during surgery. ${ }^{14-18}$ In such cases, and based on the ALARA principle, 3D CBCT imaging must be as targeted as possible to reduce patient radiation exposure to a minimum. 
CBCT is the imaging technique indicated in pre-surgical evaluation for extraction of third upper molars where orthopantomography suggests contact between the tooth (roots) and the maxillary sinus floor. ${ }^{19-21}$ In these cases as well, based on the ALARA principle, 3D imaging (CBCT) must be as targeted as possible to reduce patient radiation exposure to a minimum.

\section{TOOTH TRANSPOSITION}

Tooth transposition is an eruption anomaly, defined as the positional interchange of two neighbouring teeth. This anomaly, only found in permanent dentition, causes an alteration of the normal sequence in the dental arch. ${ }^{28,29}$

Tooth transposition may be found in two forms, complete (true/complete transposition) and incomplete (pseudo/ incomplete transposition). ${ }^{30}$

In its complete form, transposition involves the whole permanent tooth (crown and root), while, in the incomplete form, only the crown is involved.

Transposition is a relatively rare, usually unilateral, anomaly, which prevalence in the population is around $0.3 \% .{ }^{28}$ It is more frequently found in female patients (female/male ratio 3:1) and in the upper arch, ${ }^{29}$ and it is often associated with other dental anomalies. ${ }^{31}$ In most cases, tooth transposition occurs between the canine and the neighbouring teeth, in particular between the upper canine and first premolar, followed by transposition between the upper canine and lateral incisor $(28,29)$.

The aetiology of tooth transposition remains unknown to date. It is presumed to be of a multifactorial origin (genetic, traumatic, anatomical, etc.).

\section{Recommendation no. 1}

On suspicion of tooth transposition, level I radiological investigation should not be carried out earlier than the age of six

Strength of recommendation: A Degree of Evidence: I At age 6 , permanent tooth buds, third molars excepted, are visible on the panoramic image. Nevertheless, prescription of such examination for suspected tooth transposition must be evaluated considering the patient's medical history, clinical signs and symptoms and the risk/benefit ratio in exposing the patient to such radiological investigation.

\section{Recommendation no. 2}

On suspicion of tooth transposition, the indicated level I radiological investigation is orthopantomography, which may be sufficient for treatment planning

Strength of recommendation: A Degree of Evidence: I Level I radiographic investigations are the first step in the diagnos- tic approach to tooth transposition, and the panoramic image is indicated in order to confirm diagnostic suspicion. The main advantages, compared to those of intraoral images, are it shows both jaws in one single two-dimensional image, and it allows reducing exposure to radiation (10 times less than "radiographic status"). ${ }^{11}$

There is no clinical evidence supporting the use of CBCT as an initial diagnostic examination for tooth transposition. Use of the latter technique should be restricted to cases for which level I radiographic investigations cannot provide adequate information.

\section{Recommendation no. 3}

\section{$\mathrm{CBCT}$ is a useful imaging technique in assessing tooth transpositions associated with dental impaction}

Strength of recommendation: A Degree of Evidence: V In assessing complete or incomplete tooth transposition associated with impaction, of one or both transposed teeth, 3D CBCT imaging may be useful for a more accurate evaluation of the position and the inclination of the teeth/buds affected, and of the relationships between transposed teeth and adjacent structures/teeth (e.g. remodelling of the bony limits, external root resorption, etc.) and of any associated lesion.

\section{Recommendation no. 4}

\section{Intraoral periapical imaging may be used in tooth transpositions}

Strength of recommendation: B Degree of Evidence: V Periapical radiography is an imaging technique generally used in dentistry to evaluate periapical lesions, root morphology (when planning extraction/endodontic treatment) and post-implant surgery checkup. To assess tooth transposition, given its restricted anatomical vision, periapical radiography can play a role in evaluation of the location of the affected teeth/buds (complete Vs incomplete transposition), the developmental degree of the transposed teeth and their relationships with adjacent structures/teeth.

\section{NUMERICAL ANOMALIES OF TEETH}

Teeth number anomalies may concern either additional or missing teeth.

With regard to missing teeth, the absence of all teeth is called anodontia; this clinical situation is very rare and is mainly due to congenital diseases such as ectodermal dysplasia.

Oligodontia is the presence of less than $50 \%$ teeth, while hypodontia means one or more teeth (but less than 50\%) are missing. 
The presence of supernumerary teeth in the dental arches is rarely found in primary (0.3-1.7\%) and in permanent dentitions $(0.2-3.6 \%) .{ }^{31}$ Supernumerary elements are most frequently in the anterior area of the maxilla, and cause delayed and ectopic eruptions, and other eruption disorders, e.g. crowding. These are occasionally found upon diagnostic examination carried out for other reasons. Early diagnosis of this disorder is very important for early prevention/interception of eruptive complications, thus favouring physiological dentition. The typical clinical observation that should arouse suspicion of supernumerary teeth is non-symmetrical dentition in the dental arches. ${ }^{32}$

\section{Recommendation no. 1}

\section{On suspicion of numeric anomalies of teeth, a level I radiological investigation is advised after the age of 6 . Orthopantomography is the indicated $2 \mathrm{D}$ radiological imaging technique}

Strength of recommendation: A Degree of Evidence: IV Prescribing a radiographic examination for suspected dental impaction should be evaluated, considering the patient's medical record (e.g. positive family medical history), signs and symptoms (e.g. unexpected absence of a tooth, anomalous eruption of a tooth, bulging of the gingival mucosa) and the risk/benefit ratio of exposing the patient to a potentially harmful radiological investigation (exposure to ionising radiation). ${ }^{11}$

The main advantages of orthopantomography scanning, compared to intraoral radiography, are the possibility to include both jaws in one single two-dimensional image and a reduced exposure to radiation (10 times less than a "radiographic status"). ${ }^{11}$ There is no clinical evidence supporting the use of CBCT as an initial diagnostic investigation for numerical dental anomalies. Use of the latter technique should be restricted to cases where level I radiographic investigations cannot provide adequate information. Orthopantomography is the $2 \mathrm{D}$ radiological imaging technique advised for the initial assessment of numerical dental anomalies. This radiographic image provides information on the number and position of supernumerary teeth, their relationship with the alveolar ridge, the projective relationships with teeth and adjacent structures and the presence of any associated lesions (radio-transparent lesions and/or periradicular radio-opaque lesions). ${ }^{12} \mathrm{How}-$ ever, in the assessment of a supernumerary tooth that has caused dental impaction, 2D imaging techniques turn out to be less accurate than 3D CBCT. In particular, it should be considered that $2 \mathrm{D}$ imaging is significantly less effective than $3 \mathrm{D}$ imaging in establishing correct positioning of the supernumerary teeth with regard to adjacent structures (teeth and critical structures such as the mandibular canal, the nasal fossa and the maxillary sinus $)^{13}$ and also in supplying necessary information for correct surgical planning. The use of CBCT should be considered as a level II diagnostic examination, with view to establishing and planning the correct surgical strategy.

In order to assess a numerical dental anomaly, 3D CBCT imaging may be useful for a more accurate evaluation of the location and position of the supernumerary tooth or teeth, as well as of the relationships between the latter and the adjacent teeth, and any associated lesions.

In some cases, CBCT is an crucial aid in choosing the correct surgical strategy and its degree of difficulty.

\section{ANOMALIES OF TOOTH MORPHOLOGY}

Dental morphology anomalies are rare conditions, caused by developmental defects of permanent teeth as a result of dental and periodontal trauma, infections, radiation or chemotherapeutic agent related damage, or of congenital alterations associated with genetic defects. ${ }^{30,31}$

Size anomalies are known as macrodontia, microdontia and taurodontism.

The teeth that most often present anomalies of size are lateral incisors, canines and third upper molars.

Microdontia is the most frequent one and may, in some cases, be associated with syndromic conditions.

Taurodontism typically involves molars and features an elongated pulp chamber with an apical displacement of the pulp floor and the root bi-/trifurcation. ${ }^{32}$ It is determined by failure of Hertwig's epithelia sheath to invaginate at the proper level of the root. It may occur in a sporadic form or associated with hypodontia, within the picture of genetic syndromes.

The term "dilaceration" describes the presence of a sharp curvature of the root with regard to the crown. According to some authors, for a tooth to be defined as "dilacerated", the angle formed by the axis along the root must be $\geq 90^{\circ}$, while others say $\geq 20^{\circ} .{ }^{33}$ The aetiology of dilaceration is not fully known yet. The most supported explanation is that this shape anomaly results from a traumatic event, occurring to the corresponding deciduous tooth in early childhood, even though idiopathic forms are described, probably consequent upon ectopic development of the tooth germ. ${ }^{33}$

Dens invaginatus (dens in dente) is an anomaly mainly involving the upper lateral incisors and originates from infolding and consequent development of part of a tooth within another tooth.

The fusion and germination of two neighbouring permanent germs determine the formation of teeth with separate pulp chambers and completely fused, either at the level of 
the crown in the former case or with a single pulp chamber in the latter. Often, these two forms are clinically and radiologically hard to distinguish from one other. ${ }^{31}$ Germination is the merging of only the roots of two contiguous teeth. These anomalies are often associated with the presence of supernumerary teeth.

Dental anomalies of structure are rare conditions characterised by dysplasia of dental hard tissues and may be caused by genetic conditions (type I and II dentin dysplasia, dentinogenesis imperfecta, amelogenesis imperfecta) ${ }^{34}$ or be caused by severe vitamin or nutritional deficiencies, or by infections contracted during pregnancy, the neonatal period or the early childhood..$^{35}$

\section{Recommendation no. 1}

\section{On suspicion of dental morphology anomaly, a level I radiological investigation should be considered after the age of 6}

Strength of recommendation: A Degree of Evidence: I Radiographic examination for suspected dental morphology anomaly should only be prescribed considering the patient's medical records (e.g. positive medical history of congenital syndromic conditions related to genetic disoorders, dental traumas in early childhood, severe early childhood vitamin or nutritional deficiencies), the patient's clinical signs and symptoms (e.g. tooth of altered shape or size) and the risk/ benefit of exposure to a potentially harmful radiological examination (exposure to ionising radiation).

\section{Recommendation no. 2}

\section{Level I radiographic investigations (orthopantomography} and intraoral radiography) are considered suitable imaging techniques for identification and analysis of morphology anomalies

Strength of recommendation: A Degree of Evidence: IV The main advantages of the panoramic image, compared to intraoral one, include the possibility to include both jaws in one single two-dimensional image, and a reduced exposure to radiation (10 times less than a "radiographic status"). ${ }^{11}$

There is no clinical evidence supporting the use of CBCT as an initial diagnostic examination of morphological anomaly of teeth The use of the latter techniques should be restricted to cases where level I radiographic investigations do not provide adequate information.

For assessing of a dysmorphic tooth, taking periapical radiograph is mandatory before root canal treatment for diagnosis, treatment planning and follow-up.

\section{Recommendation no. 3}

When 2D imaging is insufficient to clarify the anatomical relationships of an anomalously shaped tooth with the surrounding anatomical structures, or when the internal structure of the dysmorphic dental roots needs to be better defined, the use of $C B C T$ is recommended

Strength of recommendation: A Degree of Evidence: IV In these cases, based on the ALARA principle, 3D CBCT imaging must be as targeted as possible, to reduce the patient's exposure to radiation to a minimum and, at the same time, obtain optimal spatial resolution.

\section{Bibliography}

- Peterson LJ. Principles of Management of Impacted Teeth. In: Peterson LJ, Ellis E III, Hupp JR, Tuker MR, editors. Contemporary Oral and Maxillofacial Surgery, 3rd ed. St. Louis: Mosby; 1998. p. 215-48.

- Janakiraman EN, Alexander M, Sanjay P. Prospective analysis of frequency and contributing factors of nerve injuries following third-molar surgery. J Craniofac Surg 2010;21:784-6.

- Chu FC, Li TK, Lui VK, Newsome PR, Chow RL, Cheung LK. Prevalence of impacted teeth and associated pathologies-a radiographic study of the Hong Kong Chinese population. Hong Kong Med J. 2003 Jun;9(3):15863.

- Santosh P. Impacted mandibular third molars: review of literature and a proposal of a combined clinical and radiological classification. Ann Med Health Sci Res 2015; 5:229-34.

- Guerrero ME, Shahbazian M, Elsiena Bekkering G, Nackaerts O, Jacobs R, Horner K. The diagnostic efficacy of cone beam CT for impacted teeth and associated features: a systematic review. J Oral Rehabil. 2011;38:208-16.

- Bedoya MM, Park JH. A review of the diagnosis and management of impacted maxillary canines. J Am Dent Assoc 2009;140:1485-93.

- Elsey MJ, Rock WP. Influence of orthodontic treatment on development of third molars. Br J Oral Maxillofac Surg. 2000 Aug;38(4):350-3.

- Archer WH. Oral Surgery: A Step-By-Step Atlas of Operative Techniques, 4th ed. Philadelphia: W.B. Saunders Company; 1966. p. 507-10.

- Mortazavi H, Baharvand M, Rahmani S, Jafari S, Parvaei P. Radiolucent rim as a possible diagnostic aid for differentiating jaw lesions. Imaging Sci Dent 2015; 45:253-61. 
- Mortazavi H, Baharvand M. Jaw lesions associated with impacted tooth: A radiographic diagnostic guide. Imaging Sci Dent. 2016 Sep;46(3):147-57.

- Razi T, Moslemzade SH, Razi S. Comparison of linear dimensions and angular measurements on panoramic images taken with two machines. J Dent Res Dent Clin Dent Prospect. 2009;3:7-10.

- Horner K, Eaton K, eds. Selection criteria for dental radiology. London, UK: Faculty of General Dental Practice (UK), The Royal College of Surgeons of England; 2013.

- Chandak S, Shetty CM. Comparative study of dentascan and radiography for radiological evaluation of impacted teeth. J Clin Diagn Res. 2014 Jul;8(7):RC01-5.

- Hasegawa T., Ri S., Shigeta T., Akashi M., Imai Y., Kakei Y., Shibuya Y., Komori T. Risk factors associated with inferior alveolar nerve injury after extraction of the mandibular third molar - a comparative study of preoperative images by panoramic radiography and computed tomography. Int. J. Oral Maxillofac. Surg. 2013;42(7):843-851.

- Neves F.S., Souza T.C., Almeida S.M., Haiter-Neto F., Freitas D.Q., Bóscolo F.N. Correlation of panoramic radiography and cone beam $\mathrm{CT}$ findings in the assessment of the relationship between impacted mandibular third molars and the mandibular canal. Dentomaxillofac. Radiol. 2012;41(7):553-557.

- Matzen LH, Wenzel A. Efficacy of CBCT for assessment of impacted mandibular third molars: a review_-based on a hierarchical model of evidence. Dentomaxillofac Radiol. 2015;44(1):20140189.

- Schneider T, Filo K, Kruse AL, Locher M, Gratz KW, Lubbers HT. Variations in the anatomical positioning of impacted mandibular wisdom teeth and their practical implications. Swiss Dent J. 2014;124(5):520-38.

- Peker I, Sarikir C, Alkurt MT, Zor ZF. Panoramic radiography and cone-beam computed tomography findings in preoperative examination of impacted mandibular third molars. BMC Oral Health. 2014 Jun 14;14:71.

- Jung YH, Cho BH. Assessment of the relationship between the maxillary molars and adjacent structures using cone beam computed tomography. Imaging Sci Dent. 2012 Dec;42(4):219-24.

- Lanzer M, Pejicic R, Kruse AL, Schneider T, Gratz KW, Lubbers HT. Anatomic (positional) variation of maxillary wisdom teeth with special regard to the maxillary sinus. Swiss Dent J. 2015;125(5):555-71.

- Jung YH, Cho BH. Assessment of maxillary third molars with panoramic radiography and cone-beam computed tomography. Imaging Sci Dent. 2015 Dec;45(4):233-40.

- Botticelli S, Verna C, Cattaneo PM, Heidmann J, Melsen B. Two- versus three-dimensional imaging in subjects with unerupted maxillary canines. Eur J Orthod. 2011 Aug;33(4):344-9.

- Alqerban A, Jacobs R, Fieuws S, Willems G. Comparison of two cone beam computed tomographic systems versus panoramic imaging for localization of impacted maxillary canines and detection of root resorption. Eur J Orthod. 2011 Feb;33(1):93-102.

- Rossini G, Cavallini C, Cassetta M, Galluccio G, Barbato E. Localization of impacted maxillary canines using cone beam computed tomography. Review of the literature. Ann Stomatol (Roma). 2012 Jan;3(1):14-8.

- Jawad Z, Carmichael F, Houghton N, Bates C. A review of cone beam computed tomography for the diagnosis of root resorption associated with impacted canines, introducing an innovative root resorption scale. Oral Surg Oral Med Oral Pathol Oral Radiol. 2016.

- Danielsen JC, Karimian K, Ciarlantini R, Melsen B, Kjær I. Unilateral and bilateral dental transpositions in the maxilla-dental and skeletal findings in 63 individuals. Eur Arch Paediatr Dent. 2015 Dec;16(6):467-76. https:// doi.org/10.1007/s40368-015-0196-6.

- Cho SY, Chu V, Ki Y. A retrospective study on 69 cases of maxillary tooth transposition. J Oral Sci. 2012;54(2):197-203.

- Celikoglu M, Miloglu O, Oztek O (2010) Investigation of tooth transposition in a non-syndromic Turkish Anatolian population: characteristic features and associated dental anomalies. Med oral Patol Oral Cir Bucal e716-720.

- Celikoglu M, Kamak H, Yildirim H, Ceylan I. Investigation of the maxillary lateral incisor agenesis and associated dental anomalies in an orthodontic patient population. Med Oral Patol Oral Cir Bucal. 2012;17:e1068-73.

- Brook AH, Jernvall J, Smith RN, Hughes TE, Townsend GC. The dentition: the outcomes of morphogenesis leading to variations of tooth number, size and shape. Aust Dent J. 2014 Jun;59 Suppl 1:131-42.

- Klein OD, Oberoi S, Huysseune A, Hovorakova M, Peterka M, Peterkova R. Developmental disorders of the dentition: an update. Am J Med Genet C Semin Med Genet. 2013 Nov;163C(4):318-32.

- Luder HU. Malformations of the tooth root in humans. Front Physiol. 2015 Oct 27;6:307.

- Topouzelis N, Tsaousoglou P, Pisoka V, Zouloumis L. Dilaceration of maxillary central incisor: a literature review. Dent Traumatol. 2010 Oct;26(5):427-33.

- Kim JW, Simmer JP. Hereditary dentin defects. J Dent Res. 2007 May;86(5):392-9.

- Dreizen $S$. The mouth as an indicator of internal nutritional problems. Pediatrician. 1989;16(3-4):139-46. 
- Zhu M, Liu C, Ren S, Lin Z, Miao L, Sun W. Fusion of a supernumerary tooth to right mandibular second molar: a case report and literature review. Int J Clin Exp Med. 2015 Aug 15;8(8):11890-5.

\section{Diagnostic imaging in dental traumatology}

For dento-alveolar traumatology, please refer to "Guidelines for prevention and clinical management of dental trauma in children and adolescents" $(2012)(1,11, \mathrm{~A})$.

Diagnostic imaging in dental trauma is used to evaluate the degree of root formation of the tooth affected by trauma and to assess tooth displacement or possible root fracture. However, radiological examination should always be preceded by a thorough clinical and anamnestic evaluation. In case of tooth avulsion, intrusive luxation should be excluded in the impossibility of retrieving the missing tooth. Intrusive luxation is defined as tooth displacement into the alveolar bone. If complex lip laceration is present, some additional imaging should be taken to exclude penetration of foreign bodies in the soft tissues.

\section{Recommended procedure $\mathbf{n . 1}$}

\section{Ortopantomography (OPT) is not recommended in cases of localised dental trauma}

Strength of recommendation: A Degree of Evidence: IV OPT is a two-dimensional imaging technique which has a lower spatial resolution compared to intraoral X-ray in the evaluation of localised dento-alveolar trauma. OPT requires a 10-15 s exposure time, leading to possible movement artifacts mostly in preschool-aged children, due to poor collaboration (2-11).

\section{Recommended procedure no. 2}

\section{Periapical intraoral $\mathrm{x}$-ray is necessary in the diagnostic investigation of dento-alveolar trauma in paediatric patients}

Strength of recommendation: A Degree of Evidence: IV Periapical intraoral $\mathrm{X}$-ray performed with an adequate paralleling system is the imaging technique of choice, which finds indication in identifying dento-alveolar modifications subsequent to localised trauma. In the majority of cases, periapical $\mathrm{x}$-ray provides sufficient information for treatment planning $(3,12)$.

\section{Recommended procedure $\mathbf{n . 3}$}

CBCT is indicated for further study of selected cases, in which primary investigation provided by periapical $x$-ray does not provide sufficient information for treatment planning

Strength of recommendation: A Degree of Evidence: IV CBCT finds application in dental traumatology when clinical evaluation and primary radiographic investigations are not exhaustive for correct treatment planning $(16,17)$.

Moreover, CBCT finds application when clinical evaluation and periapical $\mathrm{x}$-ray hypothesise the presence of root fracture and/or alveolar bone fracture. In these cases, CBCT can confirm the possible presence of a fracture and help in the evaluation of the fracture line on the buccal-lingual plane, whereas two-dimensional imaging cannot provide adequate information for treatment planning $(2,13,14,15)$.

Another application of CBCT is in the diagnosis of tooth luxation, a condition often difficult to assess using twodimensional imaging.

In the aforementioned cases, CBCT imaging should respect the ALARA principle, by reducing FOV dimension and minimising radiation dose to the patient.

\section{Bibliography}

- Glendor U. Epidemiology of traumatic dental injuries - a 12 year review of the literature. Dent Traumatol 2008;24:603-11.

- Guideline on Prescribing Dental Radiographs for Infants, Children, Adolescents, and Persons with Special Health Care Needs.http://www.aapd.org/media/Policies_Guide lines/E_radiographs.pdf.

- American Dental Association Council on Scientific Affairs. Dental Radiographic Examinations: Recommendations for Patient Selection and Limiting Radiation Exposure; 2012.

- Govindarajan M, Reddy VN, Ramalingam K, Durai KS, Rao PA, Prabhu A. Prevalence of traumatic dental injuries to the anterior teeth among three to thirteen-yearold school children of Tamilnadu. Contemp Clin Dent. 2012 Apr;3(2):164-7. https://doi.org/10.4103/0976237x.96819.

- Emerich K, Gazda E. Review of recommendations for the management of dental trauma presented in first-aid textbooks and manuals. Dent Traumatol. 2010 Jun;26(3):212-6. https://doi.org/10.111 $1 / \mathrm{j} .1600-9657.2010 .00900 . x$.

- Andreasen JO, Lauridsen E, Gerds TA, Ahrensburg SS. Dent Traumatol. Dental Trauma Guide: a source 
of evidence-based treatment guidelines for dental trauma. 2012 Oct;28(5):345-50. DOI: 10.1111/j. 16009657.2011.01059_1.x.

- Clinical application of 'Justification' and 'Optimization' principle of ALARA in pediatric CT imaging: How many children can be protected from unnecessary radiation?-European Journal of Radiology.

- H. Oikarinen, S. Merilainen, E. Paakko, A. Karttunen, M.T. Nieminen, O., Tervonen, Unjustified CT examinations in young patients, Eur. Radiol. 19(2009) 11611165.

- Dental Radiographic Examinations: Recommendations For Patient Selection And Limiting Radiation Exposure. American Dental Association Council on Scientific Affairs, U.S. DEPARTMENT OF HEALTH AND HUMAN SERVICES Public Health Service, Food and Drug Administration, REVISED: 2012.

- Dental Trauma Guide 2010_produced in cooperation with the Resource Centre for Rare Oral Diseases and Department of Oral and Maxillo-Facial Surgery at the University Hospital of Copenhagen-Last edited 07-01-2014.

- Health Protection Agency: The Radiation Protection Implications of the Use of Cone Beam Computed Tomography (CBCT) in Dentistry-What You Need to Know. http://www.sedentexct.eu/content/nationalguidance-cbct.

- Bernardes RA, deMoraes IG, Hungaro Duarte MA, Azevedo BC, de Azevedo JD, Bramante CM. Use of cone beam volumetric tomography in the diagnosis of root fractures. Oral Surg Oral Med Oral Pathol Oral Radiol Endod 2009; 108:270-277.

- Cohenca N, Simon JH, Mathur A, Malfaz JM. Clinical indications for digital imaging in dentoalveolar trauma. Part 1: traumatic injuries. Dental Traumatol 2007a; 23:95-104.

- Detection of vertical root fractures in endodontically treated teeth by a cone beam computed tomography scan. J Endod 2009;35:719-722.

- Guidelines for the management of traumatic dental injuries. III. Primary teeth. Dental Traumatology 2007; https ://doi.org/10.1111/j.1600-9657.2007.00627.x.

- AAE and AAOMR Joint Position Statement. Use of Cone Beam Computed Tomography in Endodontics 2015 Update. Journal of Endodontics. http://dx.DOI. org/10.1016/jjoen.2015.07.013.

- Use of Cone Beam Computed Tomography in Endodontics 2015 Update Glendor U. Epidemiology of traumatic dental injuries - a 12 year review of the literature. Dent Traumatol 2008;24:603-11.

\section{Webliography}

A http://www.salute.gov.it/imgs/C_17_pubblicazi oni_1872_allegato.pdf.

Table of Recommendations

Diagnostic imaging for caries and periodontal disease.

1. The radiographic examination of choice for all patients suspected of having caries in primary teeth is a bitewing $\mathrm{X}$-ray.

This examination may be followed by an intraoral periapical X-ray, if the patient is defined as "at high caries risk".

Further radiographic examinations are not justified.

2. In all patients, when carious lesions are suspected in permanent teeth, the favoured radiographic image of choice is the bitewing.

This film size is large enough to evaluate the whole crown of a permanent tooth. A second intraoral periapical X-ray should be taken in case of suspected infection involving the pulp or apex.

3. Swelling of the periapical tissues in primary or permanent dentition justifies intraoral X-ray examination, preferably using a dedicated film holder and beam aiming device.

Exams such as CBCT are not indicated in this diagnostic phase.

4. If a fistula is present, diagnosis requires the intraoral radiograph to be taken with a gutta-percha cone inserted inside the fistula.

5. X-ray examination of a perma- Strength of recommendation: $B$

nent tooth showing infection signs Degree of Evidence: III on the marginal gingiva seems to be indicated especially for patients with confirmed high risk of periodontal disease.

6. Taking intraoral X-rays with dedicated holders and beam aiming devices is indicated for partial or complete RCT, pulp regeneration or canal shaping prior to root filling.
Strength of recommendation: A Degree of Evidence: I

Strength of recommendation: A Degree of Evidence: I

Strength of recommendation: A Degree of Evidence: III

Strength of recommendation: A Degree of Evidence: III

Degree of Evidence: II 
7. Intraoral X-ray is indicated for assessment, over time, of the periapical and pulp health conditions of permanent teeth that have undergone conservative treatment of the dental pulp. The followup images should be taken three months, six months, one year, since the end of therapy and then annually for the next three years.

8. Intraoral X-ray is indicated for periapical health condition periodical assessment of mature or immature teeth that have undergone provisional endodontic treatment (apecification), pulp regeneration or definitive RCT. Radiohraphic follow-up is recommended after three months, six months and then annually for the next three years, depending on the clinical situation.

Diagnostic imaging in orthodontics and gnathology.

1. For a correct orthodontic diagno- Strength of recommendation: A sis, a panoramic radiograph and a Degree of Evidence: I teleradiograph are necessary.

2. Limit prescription of CBCT and, Strength of recommendation: A preferably, use small and medium Degree of Evidence: I FOVs.

3. The use of CBCT for cephalometric diagnosis in orthodontic patients with moderate-light malocclusion is strongly discouraged.

4. Posterior-anterior teleradiography, with related cephalometric analysis, requires a highly experienced clinician.

5. For TMJ ligament-capsule tissue disorders, MRI is recommended.

For TMJ bone disease, a CBCT or

CT scan prescription is indicated.

The OPT is of no diagnostic use in these cases.

Diagnostic imaging in cranio-maxillofacial malformations.

\begin{tabular}{|c|c|}
\hline $\begin{array}{l}\text { 1. Diagnosis of cleft lip and palate } \\
\text { is strictly clinical. }\end{array}$ & $\begin{array}{l}\text { Strength of recommendation: A } \\
\text { Degree of Evidence: I }\end{array}$ \\
\hline $\begin{array}{l}\text { 2. Diagnosis craniostenosis strictly } \\
\text { clinical, but CT may be of assis- } \\
\text { tance. }\end{array}$ & $\begin{array}{l}\text { Strength of recommendation: A } \\
\text { Degree of Evidence: II }\end{array}$ \\
\hline $\begin{array}{l}\text { 3. MSCT or CBCT may be } \\
\text { indicated for analysis of I and II } \\
\text { branchial arch syndrome crani- } \\
\text { ofacial defects with the purpose } \\
\text { of treatment planning. }\end{array}$ & $\begin{array}{l}\text { Strength of recommendation: A } \\
\text { Degree of Evidence: II }\end{array}$ \\
\hline
\end{tabular}

Strength of recommendation: A Degree of Evidence: II

Strength of recommendation: A Degree of Evidence: II

Strength of recommendation: A Degree of Evidence: I

Strength of recommendation: A Degree of Evidence: I

Strength of recommendation: A Degree of Evidence: I

Use of radiological diagnosis in dental anomalies: impaction, transposition, numerical and morphology anomalies.

1. On suspicion of dental impaction, level I radiological examination must not be carried out before the age of 6 .

2. For suspected dental impaction, orthopantomography is the first diagnostic examination.

3. Level I radiographic investigations are an efficient tool in defining the risk of injuring the alveolar nerve and, in non-critical cases, may be considered sufficient in treatment planning for the extraction of a III lower molar.

4. Panoramic imaging may be appropriate for assessment III upper molar impaction and its treatment planning.

5. Level I radiographic investigations are not deemed to be an adequate imaging technique for identification and characterisation of external root resorption.

6. Periapical intraoral imaging may be used for dental impaction of the upper incisor-canine region.

7. CBCT is an essential imaging technique in assessing the relationship between third lower molars, mandibular canal and the surrounding anatomical structures and, similarly, those between third upper molars and the maxillary sinus floor.

Strength of recommendation: A Degree of Evidence: I

Strength of recommendation: A Degree of Evidence: IV

Strength of recommendation: A Degree of Evidence: IV

Strength of recommendation: $B$ Degree of Evidence: IV

Strength of recommendation: A Degree of Evidence: IV

Strength of recommendation: $B$ Degree of Evidence: IV

Strength of recommendation: A Degree of Evidence: IV

1. On suspicion of dental morphol- Strength of recommendation: A ogy anomaly, a level I radiological investigation should be considered after the age of 6 .

2. If tooth transposition is suspected, the indicated level I radiological investigation is orthopantomography, which may be a sufficient tool for treatment planning.

3. CBCT is a useful imaging technique useful in assessment of tooth transpositions associated with dental impaction.

4. Intraoral periapical imaging may be used in tooth transpositions.

1. On suspicion of numeric anomalies of teeth, a level I radiological investigation is advised after the age of 6. Orthopantomography is the indicated 2D radiological imaging technique.
Degree of Evidence: I

Strength of recommendation: A Degree of Evidence: I

Strength of recommendation: A Degree of Evidence: $V$

Strength of recommendation: $B$ Degree of Evidence: $V$

Strength of recommendation: A Degree of Evidence: IV 


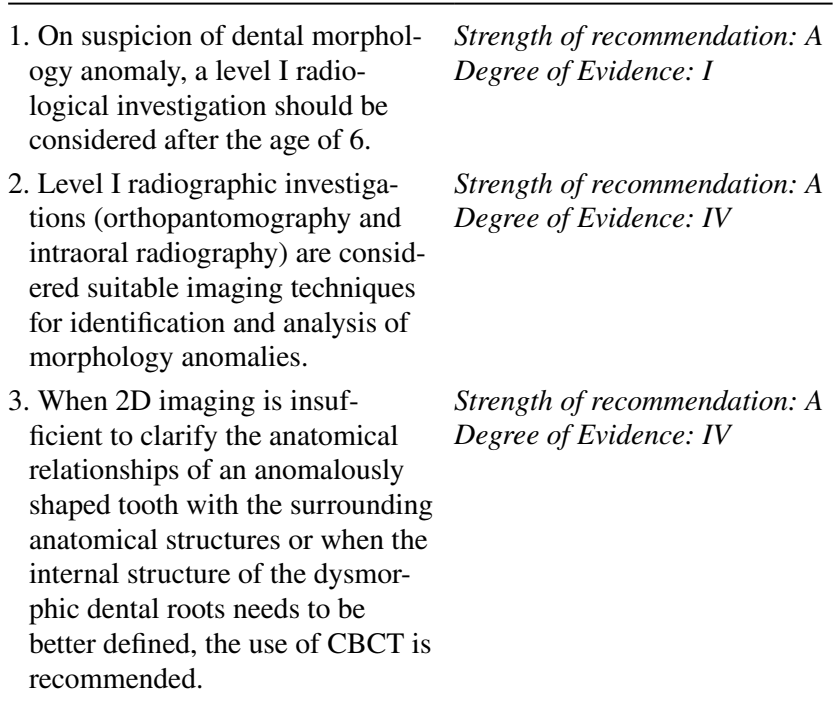

Diagnostic imaging in dental traumatology.

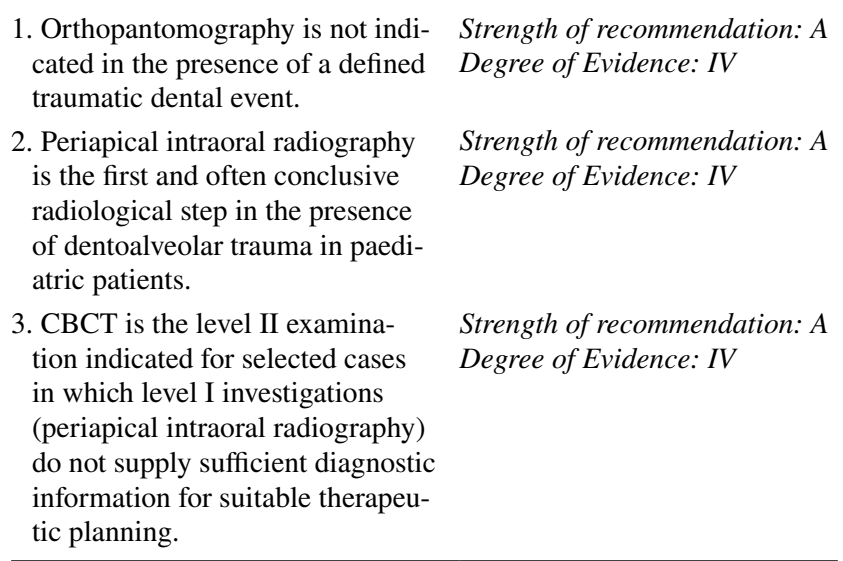

\section{Glossary}

ALARA-As Low As Reasonably Achievable: each exposure to radiation must be kept as low as it is reasonably achievable base on both economic and social considerations. This principle is mostly used, whereas exposure limits are not defined by a threshold, but on the basis of the 'acceptable risk'. Under these circumstances, it is reasonable to minimise a risk that may be presumed to exist also at levels lower than the recommended limits, considering that what makes a risk acceptable may vary greatly from one individual to another.

Lead-lined collar: individual protection device for the thyroid.

Developmental years: the age of individuals between 0 and 18 years.

FOV - Field of View: the field of investigation prescribed in order to avoid subjecting the patient to useless radiation with areas of acquisition that are over-extensive with regard to the district under examination. Availability of different FOVs (small, medium, large) depends on the device used.

IOTN_Index of Orthodontic Treatment Need: devised to rate the need for an orthodontic treatment based on dental position alterations that may be associated with selected functional alterations. Besides being used for epidemiological research, it is also used as a tool by the National Health Service to assess children's orthodontic treatment priority and eligibility for free care. The IOTN index has 5 classes for orthodontic condition grading.

DRLs-Diagnostic Reference Levels: radiation dose levels for each diagnostic imaging system or, in nuclear medicine diagnostics, levels of activity, for each type of examination, performed with standard appliances, for groups of patients of standard body size or for standard dummies. These levels should not be exceeded for standard procedures, in consideration of correct and normal applications of the diagnostic and technical procedure.

Optimisation: a series of actions that allow using the lowest possible dose suitable for the quality of the image required and necessary to obtain the desired diagnostic information.

\section{Compliance with ethical standard}

Conflict of interest The members of this work group hereby declare having no conflict of interests.

Ethical statement This article does not contain any studies with human participants or animals performed by any of the authors.

Publisher's Note Springer Nature remains neutral with regard to jurisdictional claims in published maps and institutional affiliations. 